\title{
Selective and Divided Attention during Visual Discriminations of Shape, Color, and Speed: Functional Anatomy by Positron Emission Tomography
}

\author{
Maurizio Corbetta, ${ }^{1}$ Francis M. Miezin, ${ }^{1}$ Susan Dobmeyer, ${ }^{2}$ Gordon L. Shulman, ${ }^{1}$ and Steven E. Petersen' \\ 'Department of Neurology and Neurological Surgery, and the McDonnell Center for the Study of Higher Brain Function, \\ Washington University School of Medicine, St. Louis, Missouri 63110 and ${ }^{2}$ Department of Neurology, University of lowa, \\ lowa City, lowa 52242
}

Positron emission tomography (PET) was used to identify the neural systems involved in discriminating the shape, color, and speed of a visual stimulus under conditions of selective and divided attention. Psychophysical evidence indicated that the sensitivity for discriminating subtle stimulus changes in a same-different matching task was higher when subjects selectively attended to one attribute than when they divided attention among the attributes.

PET measurements of brain activity indicated that modulations of extrastriate visual activity were primarily produced by task conditions of selective attention. Attention to speed activated a region in the left inferior parietal lobule. Attention to color activated a region in the collateral sulcus and dorsolateral occipital cortex, while attention to shape activated collateral sulcus (similarly to color), fusiform and parahippocampal gyri, and temporal cortex along the superior temporal sulcus.

Outside the visual system, selective and divided attention activated nonoverlapping sets of brain regions. Selective conditions activated globus pallidus, caudate nucleus, lateral orbitofrontal cortex, posterior thalamus/colliculus, and insular-premotor regions, while the divided condition activated the anterior cingulate and dorsolateral prefrontal cortex.

The results in the visual system demonstrate that selective attention to different features modulates activity in distinct regions of extrastriate cortex that appear to be specialized for processing the selected feature. The disjoint pattern of activations in extravisual brain regions during selective- and divided-attention conditions also suggests that perceptual judgments involve different neural systems, depending on attentional strategies.

\footnotetext{
Received Nov. 12, 1990; revised Jan. 28, 1991; accepted Mar. 6, 1991.

We thank Drs. Michael I. Posner, David L. Robinson, and Marcus E. Raichle for helpful comments on the manuscript and Helen Messmer and Susan Furey for editorial assistance. This work was supported by NIH Grants NSO6833, NS25233, and EY08775, by ONR Grant N00014-89-J-1426, and by the McDonnell Center for the Study of Higher Brain Function. M.C. was supported by an FIDIA fellowship and a grant from the University of Verona, Italy.

Correspondence should be addressed to Steven E. Petersen, Department of Neurology and Neurological Surgery, Washington University School of Medicine, Box 8111 , St. Louis, MO 63110 .

Copyright (c) 1991 Society for Neuroscience $0270-6474 / 91 / 112383-20 \$ 03.00 / 0$
}

It is a common experience that searching for a friend in a crowd is aided by the knowledge that he or she is wearing a red coat. The ability to select, or focus on, a small fraction of the incoming sensory information eases the computational load in analyzing environmental scenes and planning responses coherent with behavioral goals. Understanding how the brain solves the problem of selecting relevant information is a major goal for both cognitive and neural sciences.

Early selection theorists have suggested that selection is based on simple stimulus characteristics of the sensory signal (Broadbent, 1958, 1982; Kahneman and Treisman, 1984), while late selection theorists have argued that selection occurs after stimulus identification or semantic encoding, perhaps controlling the transfer of information to short-term memory ${ }^{1}$ (Deutsch and Deutsch, 1963; Duncan, 1980).

Both early and late models of selection have been supported by experimental findings and have been widely discussed (for reviews, see Broadbent, 1982; Kahneman and Treisman, 1984; Johnston and Dark, 1986; Allport, 1989). However, neither early nor late mechanisms appear to account for the existing experimental evidence completely. A selective mechanism, or mechanisms, may act at many different points during processing, affecting a variety of computations that depend on task demands (Ullman, 1984).

Single-unit recording studies in behaving animals provide further evidence for multiple loci of selection. Spatial attention modulates visual processing at several levels of the processing hierarchy, including posterior parietal cortex (Robinson et al., 1978; Bushnell et al., 1981) and lateral pulvinar (Petersen et al., $1985,1987)$, areas that have been associated with visuospatial analysis and visual orienting (Andersen, 1987, 1989). Spatially selective enhancement conditioned on overt movements occurs in dorsolateral prefrontal cortex (Boch and Goldberg, 1989), frontal eye fields (Bushnell et al., 1981; Bruce and Goldberg, 1985), superior colliculus (Wurtz and Goldberg, 1972; Wurtz et al., 1980), and some caudate subdivisions (Hikosaka et al., $1989 \mathrm{a}$ ), areas thought to be more involved in spatial memory, executive functions, and motor planning (Fuster, 1985; Goldman-Rakic, 1988). Enhancement for specific features of a visual stimulus, such as its orientation or color, has been described in

\footnotetext{
' Van der Heijden (1981) has noted that this controversy has collapsed two different issues: (1) what features can be analyzed in parallel and (2) what features are used in the selection of information. Recent theories treat these two issues separately.
} 
extrastriatc cortical arca V4 (Hacnny and Schiller, 1988; Spitzcr et al., 1988) and inferotemporal cortex (IT; Richmond and Sato, 1987).

Single-unit and lesion data have suggested a distinction between the site of selective effects and the source of the signals producing the effects (Posner and Petersen, 1990). For example, the collicular-pulvinar-parietal system may be the "source" of a spatial signal used in filtering out irrelevant information in the occipitotemporal stream, which includes areas V4 and IT (Ungerleider and Mishkin, 1982; Moran and Desimone, 1985; Andersen, 1987, 1989; Wise and Desimone, 1988). Neural responsiveness in occipitotemporal area V4 and area IT is gated by the position of spatial attention in the visual field (Moran and Desimone, 1985), and inactivation of the lateral pulvinar impairs a monkey's ability to focus attention during an object recognition task (Desimone et al., 1989). Areas V4 and IT are thus hypothesized to be the "recipient" or the "site" of spatial selectivity generated in posterior parietal cortex and funneled to these areas through the pulvinar.

The present study attempts to address these issues in selective attention in humans in terms of both behavioral performance and the neural mechanisms underlying that performance. We report here psychophysical performance and positron emission tomography (PET) functional mapping experiments on visual attention to the color, speed, and shape of objects in visual stimulus arrays.

Some of these results have been presented in abbreviated form elsewhere (Corbetta et al., 1990a).

\section{Materials and Methods}

\section{Subjects}

Subjects were normal volunteers drawn from the population of students, residents, and fellows in the medical, allied health, and graduate schools of Washington University. All were strongly right-handed as assessed by the Edinburgh handedness inventory. Volunteers ranged from 22 to $41 \mathrm{yr}$ of age, and all reported normal or corrected-to-normal visual acuity. Informed consent was obtained following guidelines approved for this study by the Human Studies Committee of Washington University. Eleven volunteers (seven females, four males) were tested in experiment 1 , and a second group of nine volunteers (seven females, two males) was tested in experiment 2 . For this second group, informed consent forms and procedures were also approved by the Radioactive Drug Research Committee of Washington University.

\section{Apparatus}

Each subject lay on a scanner couch and wore an individually molded, closely fitted, plastic facial mask to ensure head stability (Fox et al., 1985). The room was dimly illuminated, and equipment-cooling fans produced a low-level background noise. Stimuli were generated using a Ramtek 9400 graphics display system and were displayed on an RGB monitor positioned about 13 inches from the subject, subtending a visual angle of $32^{\circ}$. Eye movements were monitored using EOGs.

\section{Psychophysical procedures}

Both experiment 1 , in which only psychophysical data were collected, and experiment 2 , in which both psychophysical and PET data were collected, involved a same-different matching task. Subjects fixated a small white spot centered on the monitor screen. Each trial consisted of two 400 -msec stimulus frames separated by a 200 -msec blank-display interval (Fig. 1). A 1500-msec response interval followed the second stimulus. Each stimulus frame consisted of a spatially random distribution of 30 elements of identical shape and color, moving horizontally as a coherent sheet either to the left or to the right. The shape, color, and/or speed of all the elements might be changed between the first and the second frame. Direction of motion was maintained constant within a trial, and randomly shifted across trials.

The subject's task was to compare the first stimulus frame with the second and report if the two frames were different for a particular stimulus feature (e.g., color). In experiment 1 , subjects pressed a key if the two frames were different and withheld a response if the two frames were the same. In experiment 2 , the subject pressed one key on "same" trials and a second key on "different" trials. Hits, defined as "different" responses on trials involving a change of the instructed feature, and false alarms, defined as "different" responses on trials with no relevant stimulus change, were recorded and $d^{\prime}$ values ${ }^{2}$ were computed.

A Pritchard 1980A photometer was used to measure luminance. The background luminance was 0.18 foot-lamberts (ft-L), measured at the center of the display. Luminance decreased from the center toward the periphery of the screen. The decrement was about $25 \%$ for red elements and $7 \%$ for green elements at $10^{\circ}$ from the center.

To minimize color adaptation, we used two separate series of colors, consisting of five slightly different green hues and five slightly different red hues. Within the two frames of a trial, colors from only one of the series were used, but across trials, one or the other series was randomly selected. As a result of equipment limitations, the colors within a series were not equiluminant. Table 1 lists the luminance (in $\mathrm{ft}-\mathrm{L}$ ) of each color, measured for a single element in the center of the screen. The percent change of each test color from the reference color is listed in brackets. The effect on performance of these luminance differences was empirically addressed and is discussed in the Results.

Both experiment 1 and experiment 2 consisted of two sessions run on successive days. During the first session, the stimulus values at which changes in shape, color, or speed could just be discriminated were determined. These values were then used in the second session to determine the effect of attention on these discriminations.

\section{Day 1: threshold setting}

Psychophysical thresholds for discriminating changes within a single stimulus feature were measured using the method of constant stimuli. One block of trials was conducted for each dimension (shape, color, and speed). Within a block, values on the tested dimension either remained constant or varied between frames of a trial (e.g., on a color block, the hue of both frames in a trial might be the same or slightly different shades of green), while values on the remaining two dimensions stayed constant. The order of presentation of the blocks was counterbalanced across subjects according to a semirandom schedule in which the "shape" block always followed the "speed" block.

Before each block, the test dimension was specified, and subjects were explicitly told about the invariance of the other two stimulus attributes. In $73 \%$ of the trials ("different" trials), the reference value of the test dimension was presented on one frame and a randomly selected test value for that dimension on the other frame; in the other $27 \%$ of the trials ("same" trials), either the reference value or a single randomly selected test value was displayed on both frames. Sixteen trials were collected for each reference-test comparison.

In the color block, each reference color (e.g., red) was tested against a pool of four other colors (test colors), each slightly different in hue from the reference (i.e., four different shades of red). The test colors had been ranked in a pilot study for degree of discriminability. One hundred seventy-six trials were run in this block. Speed and shape were constant both within and across trials at the reference values of $18 \% \mathrm{sec}$ and "square."

In the speed block, the reference speed $(18 \% \mathrm{sec})$ was randomly compared with five test speeds: $21,24,27,30$, and $33 \%$ sec; 112 trials were run. Color and shape were constant within a trial. Across trials, color was either the red or the green reference value, while shape was always square.

In the shape block, the reference shape (square, $0.8^{\circ} \times 0.8^{\circ}$ ) was compared to four rectangles: $0.9^{\circ} \times 0.7^{\circ}, 0.95^{\circ} \times 0.65^{\circ}, 1.0^{\circ} \times 0.6^{\circ}$, and $1.1^{\circ} \times 0.6^{\circ}$; the longest side was always vertical. Within a trial, color and speed were constant. Across trials, color was either the red or the green reference value, while speed was either the $18 \% \mathrm{sec}$ reference value or the threshold speed selected in the speed block. This block consisted of 176 trials.

The data collected on day 1 were used to determine for each stimulus attribute the stimulus value yielding a $d^{\prime}$ of about 1.6. These threshold values plus the reference values were used on day 2 .

\footnotetext{
${ }^{2} d$ is an index of discriminability that measures the scparation between the means of the signal and noise distributions in units of the standard deviation of the noise distribution (Green and Swets, 1966). $d^{\prime}$ is computed by subtracting the $Z$ score for false alarms from the $Z$ score for hits.
} 


\section{Day 2: feature attention}

On day 2, data were collected in blocks using the same basic paradigm as on day 1 .

During the "selective-attention" blocks, subjects were instructed to respond to changes in a single feature. On half the trials ("different" trials), the attended feature was varied either alone or together with changes in one or both of the unattended attributes (e.g., during these trials in a color block, speed and shape might stay constant in both frames, speed might change, shape might change, or both speed and shape might change). This irrelevant variation forced subjects to focus on variations of the selected stimulus attributc, filtcring and/or ignoring changes of other stimulus attributes. In the other half of the trials ("same" trials), the attended attribute was not varied, assuming on both frames either the reference or threshold value. Again, from none to two of the unattended attributes might also be changed between frames of a "same" trial. The order of presentation of reference and test values on the two frames of a trial was randomized.

In the "divided-attention" blocks, subjects were instructed to detect whether a change occurred in any feature. On half of the trials ("same" trials), all three stimulus dimensions were constant within a trial, and across trials were randomly assigned (separately for each dimension) either the reference or threshold value. On the other half of the trials ("different" trials), a single, randomly selected stimulus attribute was varied between the first and the second frame.

Design: day 2, experiment 1. Four blocks were conducted, with the order counterbalanced across subjects. The three selective-attention blocks contained 128 trials each, 16 trials at each of the factorial combinations specified by the two response types (same, different) and the four possible types of unattended variation (no change, a change in one or the other unattended feature, a change in both features). The single divided-attention block contained 96 trials: 16 trials for each single feature change and 48 trials without any change.

Design: day 2, experiment 2. During each PET scanning session, a block of 24 trials was collected for each of eight PET scans. Each block took $60 \mathrm{sec}$ and started about $10 \mathrm{sec}$ before the onset of PET data collection. For two of the scans, the subject performed the dividedattention task. For three of the scans, the subject performed the selectiveattention task, one scan being done for each of the features. For the remaining three scans, subjects performed a "passive" task in which they were instructed on each trial simply to fixate without actively discriminating the two frames and then to press either one of the two keys. The stimulus display during the passive condition was identical to that during the selective conditions. An additional "fixation-point" control scan was added during which the subject only fixated on the central spot; the two visual stimulus frames were not presented, and no key was pressed.

The order of the nine scans was counterbalanced across subjects, except for the following constraints used to minimize potential artifacts due to subject movement between each selective scan and corresponding divided and passive scans: (1) the second, fifth, and eighth scans were always passive scans, (2) the fixation point control was either the first or the last scan, and (3) two of the selective-attention scans were adjacent to divided-attention scans.

\section{PET scanning techniques}

The standard PET scanning activation methodology developed at Washington University was used. These methods are extensively described in the literature (Fox et al., 1988; Mintun et al., 1989; Pctersen ct al., $1989)$ and will be only briefly discussed here.

The subject's head was stabilized with a plastic facial mask, and a lateral skull $x$ ray was taken to assess head alignment in the scanner and the anatomical locations of the scan slices (Fox et al., 1985). Water labeled with ${ }^{15} \mathrm{O}$ acting as a blood-flow tracer was administered as an intravenous bolus of $8-10 \mathrm{ml}$ of saline containing $50-70 \mathrm{mCi}$. The use
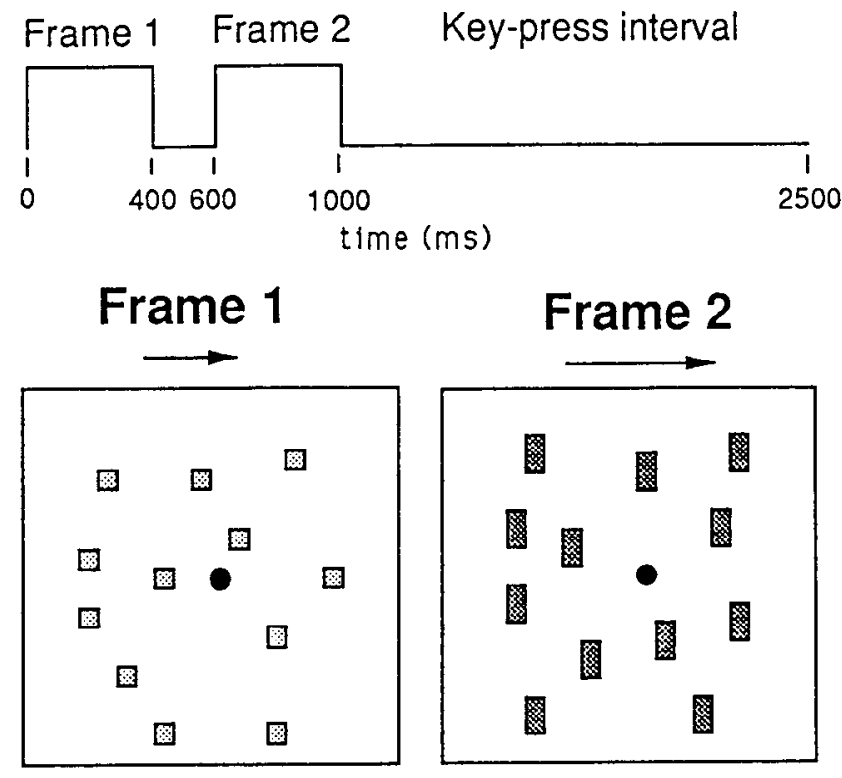

Figure 1. Stimulus display and timing of a single trial.

of ${ }^{15} \mathrm{O}$-labeled water, with its short half-life (123 sec) and short scanning time $(40 \mathrm{sec})$, allowed for the performance of nine scans within an individual in a single session.

The PETT VI system was used in the low-resolution mode, simultaneously acquiring seven parallel slices with a center-to-center distance of $14.4 \mathrm{~mm}$ (Yamamoto et al., 1982). Images were reconstructed by filtered back projection to a resolution of $18 \mathrm{~mm}$ full-width at halfmaximum (FWHM) and a pixel size of $2.7 \times 2.7 \mathrm{~mm}$. An arterial catheter was not used, and therefore the reconstructed images were not converted to blood-flow values. The responses reported here are changes in radiation distribution rather than blood-flow changes. Over the range tested, blood flow is very linear with radiation counts (Herscovitch et al., 1983). Therefore, in the text, responses will be referred to as changes in blood flow.

A linear normalization was applied to reconstructed images to negate the effects of global fluctuations in activity (Fox et al., 1987). This prevented the confounding of task-induced focal changes with fluctuations affecting the entire brain (e.g., due to changes in arterial $\mathrm{pCO}_{2}$ ). For each subject, images were grouped into activation-control pairs and subtracted from each other. Images with obvious movement artifacts were excluded from further analysis (Fox et al., 1987). The resultant images are of foci of change on a baseline noise background, rather than on the complex background of varying brain anatomy.

All subtraction images were transformed to a standard anatomical space. Those acquired during identical behavioral states were averaged across subjects to suppress image noise and improve signal-to-noise ratio (Fox et al., 1988). For all the results discussed here, averaged images that are directly compared to each other include the same group of subjects in each and every averaged image that makes up the comparison set (within-subject design).

A maximum-detection computer algorithm (Fox et al., 1988; Mintun et al., 1989) was used to identify all positive and negative local maxima in each averaged image. A two-tiered statistical analysis was applied to these sets of regional foci. First, an omnibus test (gamma-two statistic) was used to determine whether an image (a population of regional changes) had any significant responses (distribution outliers). Second, as a post hoc analysis, the magnitude of a response was described relative to the

Table 1. Luminance values (in $\mathrm{ft}-\mathrm{L}$ ) for the red and green stimulus series

\begin{tabular}{lllccc} 
& $\begin{array}{l}\text { Reference } \\
\text { color }\end{array}$ & $\begin{array}{l}\text { Test } \\
\text { color } 1\end{array}$ & $\begin{array}{l}\text { Test } \\
\text { color } 2\end{array}$ & $\begin{array}{l}\text { Test } \\
\text { color 3 }\end{array}$ & $\begin{array}{l}\text { Test } \\
\text { color 4 }\end{array}$ \\
\hline Red & 3.32 & $3.45[4]$ & $3.59[8]$ & $3.20[-4]$ & $3.45[4]$ \\
Green & 9.20 & $9.61[5]$ & $10.15[10]$ & $10.67[16]$ & $11.24[22]$ \\
\hline
\end{tabular}



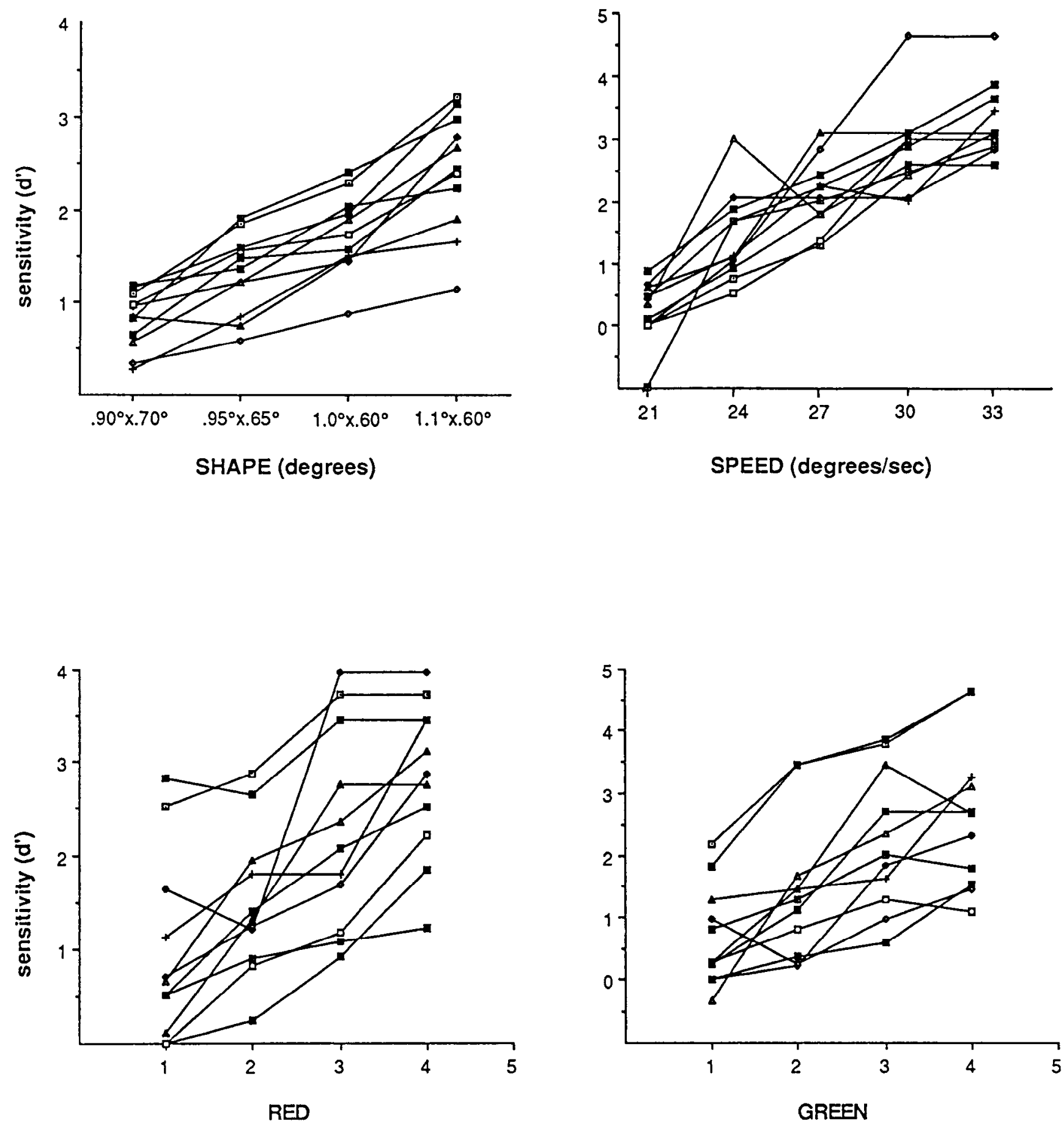

Figure 2. Psychometric functions for each subject, from experiment 1. On each $\mathrm{x}$-axis are plotted test values increasingly discrepant from reference values: for shape, test values are more elongated rectangles; for speed, test values increase in speed; for red, test values contain progressively more green; and for green, test values contain progressively more red. On the y-axis is plotted sensitivity in $d^{\prime}$ values.

noise level by $Z$ score (Fox et al., 1988). These techniques were originally developed for blood-flow-change data, but have recently also been validated for activity-change data (Fox and Mintun, 1989).

\section{Results}

\section{Experiment 1: psychophysics}

Threshold determination

Individual psychometric functions for each stimulus feature, obtained on the first day of the experiment, are plotted in Figure
2. Speed and shape discrimination yielded very reproducible performance levels across subjects, and their psychometric curves are well grouped. Threshold values were very similar in each subject, either $24 \% \mathrm{sec}$ or $27 \% \mathrm{sec}$ for speed discrimination (reference value, $18^{\circ} / \mathrm{sec}$ ) and either $0.95^{\circ} \times 0.65^{\circ}$ or $1^{\circ} \times 0.60^{\circ}$ rectangles for shape discrimination (reference value, $0.8^{\circ} \times 0.8^{\circ}$ ). Sensitivity for color discrimination was more variable across subjects. However, for each subject, it was possible to select a test value close to the desired $d^{\prime}$ value (1.6). 


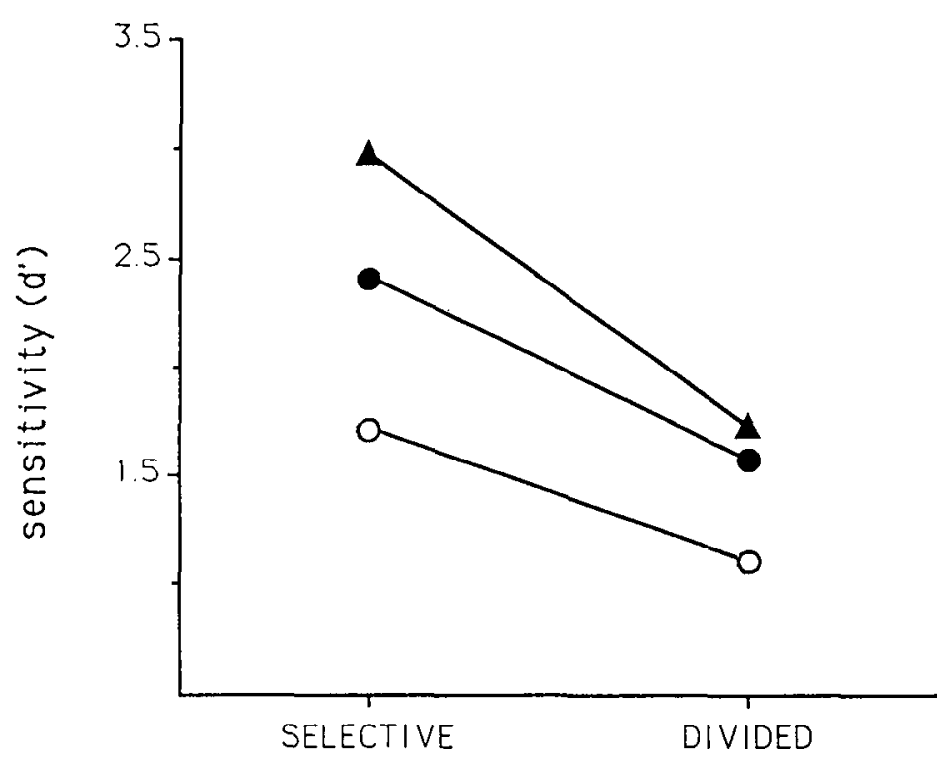

ATTENTION

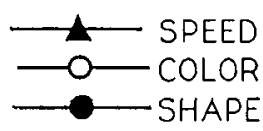

Figure 3. Sensitivity as a function of attentional condition for each stimulus feature in experiment 1.
The possibility that subjects relied on luminance cues for color discrimination was tested using pairs of stimuli, holding hue constant at the reference hues, but varying luminance over the same range as was present between the reference and the threshold test colors. The structure of the task was identical to the color discrimination task, and the same number of trials was run. This control was performed either at the end of the first day or at the beginning of the second day. In all subjects, performance was at chance when discriminating changes in luminance. Because chromatic stimuli with these same luminance changes yielded suprathreshold performance, chromatic rather than luminance information appeared to be the major cue for discrimination in the color task.

\section{Feature attention}

The influence of attention on feature discrimination was assessed by comparing sensitivity $\left(d^{\prime}\right)$ to a particular attribute change in the selective condition, in which that attribute was selectively attended, with identical trials in the divided condition, in which any attribute was attended. For the selective conditions, only those trials containing a stimulus change in the attended feature (e.g., a color change in a color block) without changes in the other features (i.e., a shape or speed change) were selected for the analysis. These trials ( $25 \%$ of the total number) were visually identical to those collected in the divided-attention condition. Repeated-measure ANOVAs on $d^{\prime}$ values were run with "feature" (shape, color, speed) and "attention" (selective, divided) as factors. Selective attention improved sensitivity, yielding a higher $d^{\prime}[F(1,10)=13.25 ; p<0.001$; Fig. 3]. The effect was similar for all three features as determined by the lack of a feature $\times$ attention interaction $[F(2,20)=0.39 ; p=\mathrm{NS}]$. Because some subjects showed either a very high percentage of hits or a very low percentage of false alarms, thus affecting the reliability of the calculation of $d^{\prime}$, the hits and false alarm rates were separately analyzed to confirm the $d^{\prime}$ analysis. Selective attention yielded both a higher percentage of hits $[F(1,10)=$
$4.67 ; p=0.05]$ and a lower percentage of false alarms $[F(1,10)$ $=18.29 ; p=0.001]$ than divided attention. ${ }^{3}$

\section{Feature interactions}

In the selective-attention task, unattended feature changes were coupled to attended feature changes on $75 \%$ of the trials. This allowed us to study whether sensitivity for changes in an attended feature was affected by changes in other features.

Unattended stimulus changes might act as noise added to the attended channel, yielding a drop in sensitivity. A two-way repeated-measures ANOVA was run with feature (shape, color, speed) and number of unattended changes $(0,1,2)$ as factors, and $d^{\prime}$ as the dependent variable. Because a single unattended change may occur in either one or the other unattended feature (e.g., either shape or speed during color discrimination), the actual valuc inscrted within the analysis was the average $d^{\prime}$ value for the two attributes. Neither the main effect of number of unattended changes $[F(2,20)=0.33]$ nor the feature $\times$ number of unattended changes interaction $[F(4,40)=0.89]$ was significant. Therefore, unattended stimulus changes did not globally affect the sensitivity for the attended feature.

Sensitivity for one feature might also be specifically influenced by simultaneous variations in another feature. For each selective

\footnotetext{
${ }^{3}$ The calculation of $d$ in this article assumes that the signal and noise distributions are normal and that their variances are equal. If these assumptions are not met, criterion changes (i.c., a greater willingness to say "different" in the selective conditions) can produce changes in $d^{\prime}$. The separate analysis of hits and false alarms, however, renders this possibility extremely unlikely. Performance differences between two conditions are caused by criterion shifts when the conditions plot at different points on the same receiver operating-characteristic curve (ROC curve). The two conditions differ in sensitivity when they plot on different ROC curves. The selective conditions yielded both significantly more hits and significantly fewer false alarms than the divided condition. If one considers the ROC curve, which is monotonic under quite general conditions (Green and Swets, 1966), it is not possible to move along the curve by increasing hits and decreasing false alarms. The separate analyses of hits and false alarms clearly imply that the two conditions plot on different ROC curves and therefore correspond to different sensitivities.
} 
Table 2. Foci of activations in primary visual cortex and surrounding regions

\begin{tabular}{|c|c|c|c|c|c|}
\hline \multirow[b]{2}{*}{ Focus/area } & & \multicolumn{3}{|c|}{ Coordinates } & \multirow[b]{2}{*}{ Magnitude } \\
\hline & & S/I & $\mathbf{L} / \mathbf{R}$ & $\mathrm{A} / \mathbf{P}$ & \\
\hline \multicolumn{6}{|l|}{ Passive-fixation point } \\
\hline 1. Area 17 & $\mathbf{L}$ & 8 & 11 & -57 & $141^{* *}$ \\
\hline \multicolumn{6}{|l|}{ Speed-passive } \\
\hline 2. Area 17 & $\mathbf{R}$ & 14 & -5 & -63 & $50^{* *}$ \\
\hline 3. Lingual gyrus & $\mathbf{R}$ & -4 & -15 & -51 & $33^{*}$ \\
\hline \multicolumn{6}{|l|}{ Speed-divided } \\
\hline 4. Area 17 & $\mathbf{R}$ & 6 & -15 & -69 & $30^{*}$ \\
\hline \multicolumn{6}{|l|}{ Color-passive } \\
\hline 5. Area 17 & $\mathbf{L}$ & 8 & 5 & -47 & 34 \\
\hline 5a. Area 17 & $\mathbf{L}$ & 13 & 5 & -51 & 33 \\
\hline 5b. Area 17 & $\bar{L}$ & 14 & 7 & -57 & 32 \\
\hline 6. Lingual gyrus & $\mathbf{L}$ & 4 & 9 & -61 & 33 \\
\hline 6a. Lingual gyrus & $\bar{L}$ & 4 & 7 & -57 & 32 \\
\hline \multicolumn{6}{|l|}{ Shape-passive } \\
\hline 7. Area 17 & $\mathrm{~L}$ & 14 & 9 & -49 & $43^{* *}$ \\
\hline 8. Area 17 & $\mathbf{R}$ & 12 & -13 & -55 & $47^{* *}$ \\
\hline 9. Lingual gyrus & $\mathbf{R}$ & 2 & -15 & -51 & $43^{* *}$ \\
\hline \multicolumn{6}{|l|}{ Shape-divided } \\
\hline 10. Area 17 & $\mathbf{R}$ & 14 & -15 & -63 & $31^{* *}$ \\
\hline \multicolumn{6}{|l|}{ Divided-passive } \\
\hline 11. Area 17 & $\mathbf{R}$ & 8 & -17 & -51 & $42^{* *}$ \\
\hline 12. Area 17 & $\mathrm{~L}$ & 12 & 17 & -61 & $32^{*}$ \\
\hline 13. Lingual gyrus & $\mathbf{L}$ & 2 & 15 & -61 & $33^{*}$ \\
\hline
\end{tabular}

Early visual regions were localized by a maximum-detection computer algorithm in intersubject-averaged images (see Materials and Methods). Numbers to the left are used in the text to identify foci of activation. $L$, left hemisphere; $R$, right hemisphere. S/I, superior $(+)$ /inferior $(-) ; \mathrm{L} / \mathrm{R}$, left $(+) /$ right $(-) ; \mathbf{A} / \mathbf{P}$, anterior $(+) /$ posterior $(-)$. The coordinates are in millimeters from a $0,0,0$ point situated at the level of the anterior and posterior commissures $(\mathrm{S} / \mathrm{I}=0)$, at the midline of the brain $(\mathrm{L} / \mathrm{R}=0)$, and anteroposteriorly halfway between the commissures $(\mathrm{A} / \mathrm{P}=0)$. The magnitude is in normalized PET counts that are linearly correlated with blood flow (see Materials and Methods). All foci of change with a $Z$ score of $>1.96$ are reported: unmarked foci, $Z$ score $>1.96(p<0.05) ;{ }^{*}, Z$ score $>2.17(p<0.03) ; * *, Z$ score $>2.58(p<0.01)$.

condition, one-way ANOVAs were run on $d^{\prime}$, comparing accuracy when no unattended changes occurred with accuracy when paired changes also occurred in one or the other or both unattended features. No significant interactions were found.

Although unattended stimulus variations did not affect sensitivity $\left(d^{\prime}\right)$, the response criterion adopted by subjects seemed to be systematically affected. A complete within-subjects analysis on $\beta$ (response criterion) was not possible because some subjects showed either ceiling or floor effect in some discriminations. An analysis with feature and number of unattended changes as factors was conducted separately for hits and false alarms. Both the percentage of hits $[F(2,20)=5.09 ; p=0.02]$ and the percentage of false alarms $[F(2,20)=6.10 ; p<0.01]$ increased monotonically with the number of unattended attributes changed in the display. Subjects were less conservative (more prone to detect a difference) when more unattended variations occurred in the display.

\section{Experiment 2: positron emission tomography}

Psychophysics

For day 1 in experiment 2, results from the threshold determination and luminance control were similar to experiment 1 .

As in day 2 of the previous experiment, only trials containing a single attribute change were compared between selective- and divided-attention conditions. For each subject, six trials (three "same" and three "different") in each selective condition, and eight trials (four "same" and four "different") in the divided condition, out of a total of 24 trials obtained during a scan, were entered in the data analysis. Because two divided-attention scans were obtained from each subject, only trials from the scan used in the subtraction images were considered for the psychophys- ical analysis; PFT and psychophysical data were thus comparable. No systematic differences in accuracy were found between the first and the second divided-attention scan.

A statistical analysis on $d^{\prime}$ was not possible because of the low number of trials that could be collected in the $40-\mathrm{sec}$ duration of a PET scan. A two-way repeated-measures ANOVA was run separately for hits and false alarms with attention (selective vs. divided) and feature (shape, speed, color) as factors. Qualitatively, the results were the same as in experiment 1. A higher percentage of hits, $77 \%$ versus $67 \%[F(1,8)=2.27, p=$ $\mathrm{NS}$, and lower percentage of false alarms, $18 \%$ versus $33 \%$ $[F(1,8)=8.34 ; p<0.02]$, were found when attention was focused on a single feature (selective attention) than when attention was divided across features (divided attention). The significant effect on false alarms, despite the low number of trials, supports the robustness and reproducibility of this feature selective-attention effect.

\section{Blood-flow responses}

Three types of image subtraction were used.

(1) In the first level of subtraction, activity obtained in the fixation-point control scan was subtracted away from activity obtained in the passive-task scan, in which subjects fixated the fixation point while stimuli were presented and pressed either of the two keys on each trial without discriminating (passivefixation point). This subtraction image should show areas activated by the simple visual processing of the stimuli. Areas related to planning and execution of the motor response (key press) might also be activated.

(2) In the second level of subtraction, activity from the passive 
early visual regions
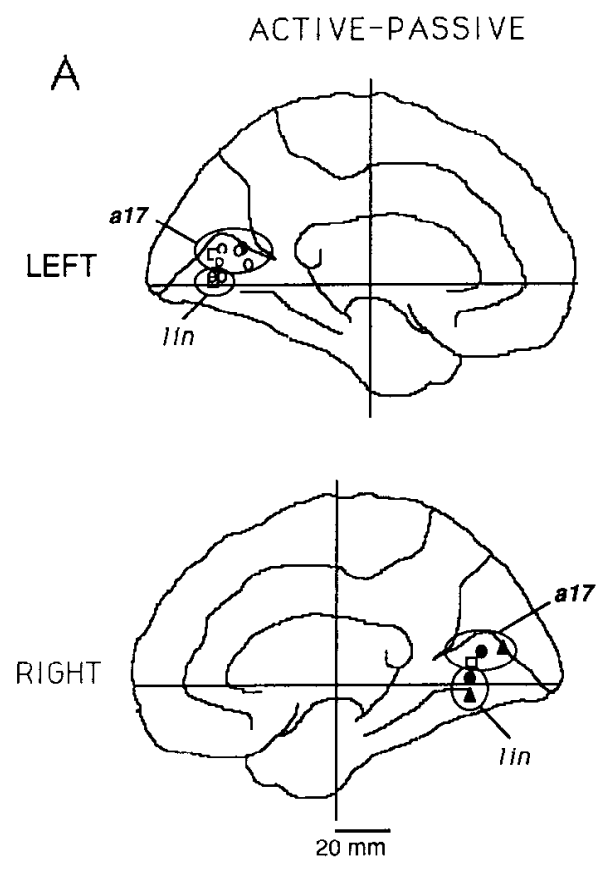

\section{SELECTIVE-DIVIDED}
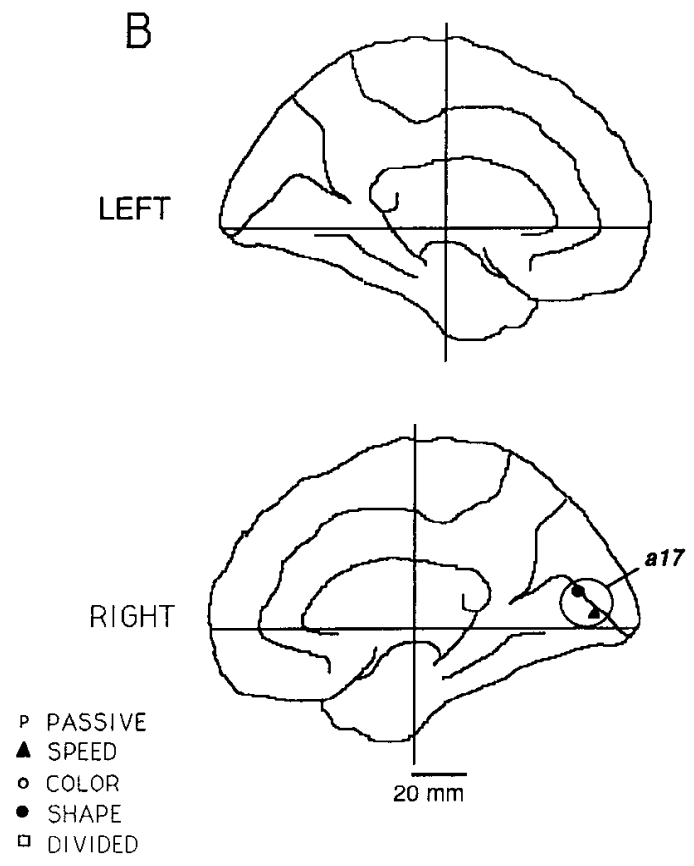

Figure 4. Outline of blood-flow activations in primary visual cortex and surrounding regions, as localized by a maximum-detection computer algorithm in intersubject averaged images (see Materials and Methods). The intersection between the two main axes represents the $0,0, x$ point in the adopted anatomical stereotactic space. $A$, Active-passive and passive-fixation point $(P)$. B, Selective-divided. $a 17$, area 17 ; lin, lingual gyrus. task was subtracted from activity for each active task (selective attention to shape, color, and speed, and divided attention; active-passive). These image subtractions match visual and motor activations. Several other factors might produce differences in the visual system between active and passive conditions. First, changes in the level of arousal as the subject moves from a passive to an active state might generally change the responsiveness of cortical and subcortical structures. Second, when engaged in a visual task, modality-specific changes may occur throughout the visual system. Finally, there may be featurespecific changes in specialized visual areas when subjects are looking for changes in a particular feature (i.e., shape, color, or speed).

The active-passive subtractions also provide comparisons between divided and selective conditions. For instance, dividedpassive might contain a low-amplitude version of some or all of the selective conditions, or might contain areas related to processes that are not present in the selective conditions.

(3) In the third level of subtraction, activity from the dividedattention condition was subtracted from activity in each of the selective-attention conditions (selective-divided). Both the divided and the selective conditions involve active engagement in a specifically visual task. Therefore, responses in the selectivedivided images should depend on feature-specific effects.

Results will be presented in three anatomically defined sections: (1) early visual regions, including primary visual cortex and surrounding regions; (2) later extrastriate visual regions; and (3) extravisual regions. In each section, all three levels of subtraction will be considered.

\section{Early visual regions}

\section{Passive-fixation point}

The strongest response was localized in medial occipital cortex (Table 2, Fig. 4A) and centered in primary visual cortex. The response was slightly left-lateralized, but clearly extended bilaterally.

\section{Active-passive}

Activations were found on the medial wall of occipital cortex in all four subtractions (divided, shape, speed, color). Responses were found at two different superior-inferior levels. One was centered about $12 \mathrm{~mm}$ above, and the other about $1 \mathrm{~mm}$ below, the anterior-posterior commissure (AC-PC) line (Table 2, Fig. $4 A$ ).

The first group of responses was localized in primary visual cortex, and the centers of these activations were shifted slightly superiorly (on average, about $4 \mathrm{~mm}$ ) in comparison to the center of the response obtained in primary visual cortex for the passive task. The second group of responses was localized on the lingual gyrus.

\section{Selective-divided}

Activations on the medial wall of the occipital lobe were significantly decreased in all three selective conditions when subtracting away the divided-attention task (Table 2, Fig. $4 B$ ). In primary visual cortex, responses obtained for attention to speed and shape were decreased (Table 2 , foci 2 vs. 4,8 vs. 10), and the response for color failed to reach significance. In the lingual gyrus, no significant activations were obtained in any of the selective conditions.

In summary, in primary visual cortex and adjacent cortical regions, more activity was evident in active than in passive conditions. The magnitude of activations in each selective condition consistently dropped in the subtraction with the dividedattention task, in which arousal and other nonspccific effects were closely matched.

\section{Extrastriate visual regions}

\section{Passive-fixation point}

A single focus was detected in extrastriate visual cortex. The center of the response was in the right fusiform gyrus (Table 3, Fig. 5). 
Figure 5. Outline of blood-flow activations in extrastriate visual cortex: active-passive and passive-fixation point $(P)$. coll, collateral sulcus; fus, fusiform gyrus; $p h$, parahippocampal gyrus; $c a$ pos, intersection of calcarine and parieto-occipital sulci; lo, lateral occipital gyrus; dlo, dorsolateral occipital cortex; ipl, inferior parietal lobule; sts, superior temporal sulcus.
Figure 6. Outline of blood-flow activations in extrastriate visual cortex: selective-divided. Abbreviations of anatomical regions are as in Figure 5.
LEFT

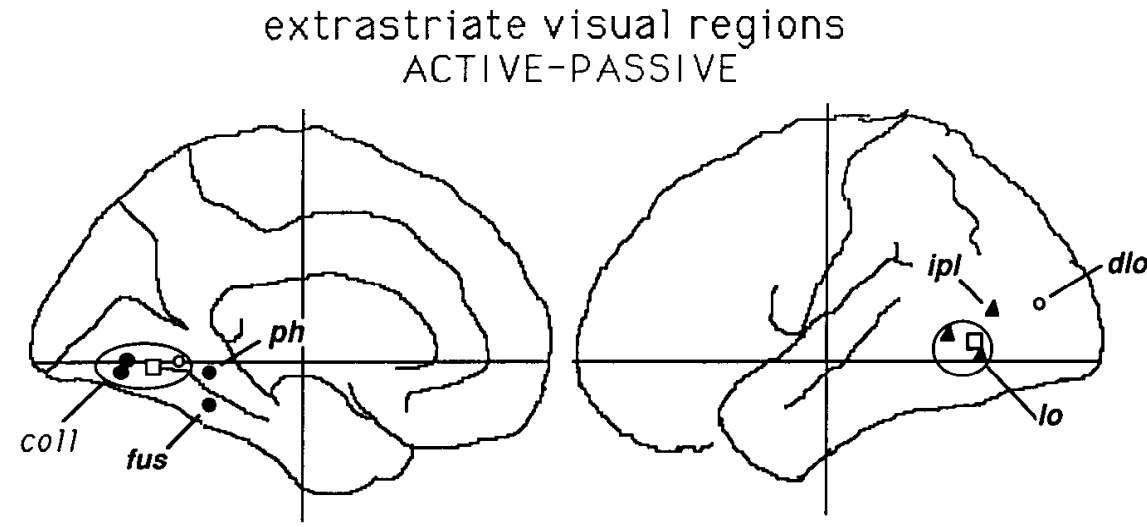

RIGHT
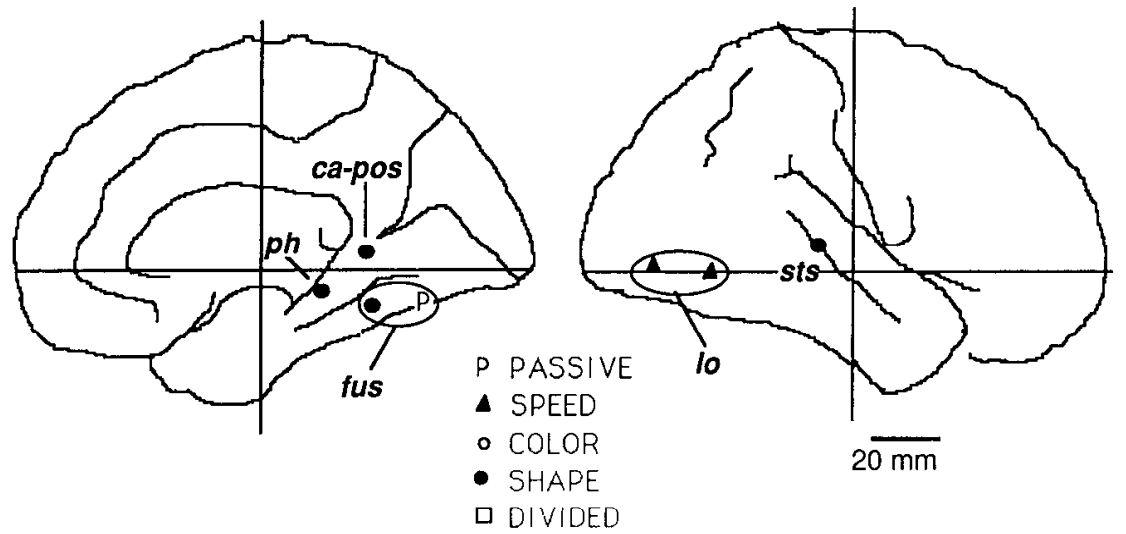

$2 \overline{\mathrm{mm}}$

\section{LEFT}

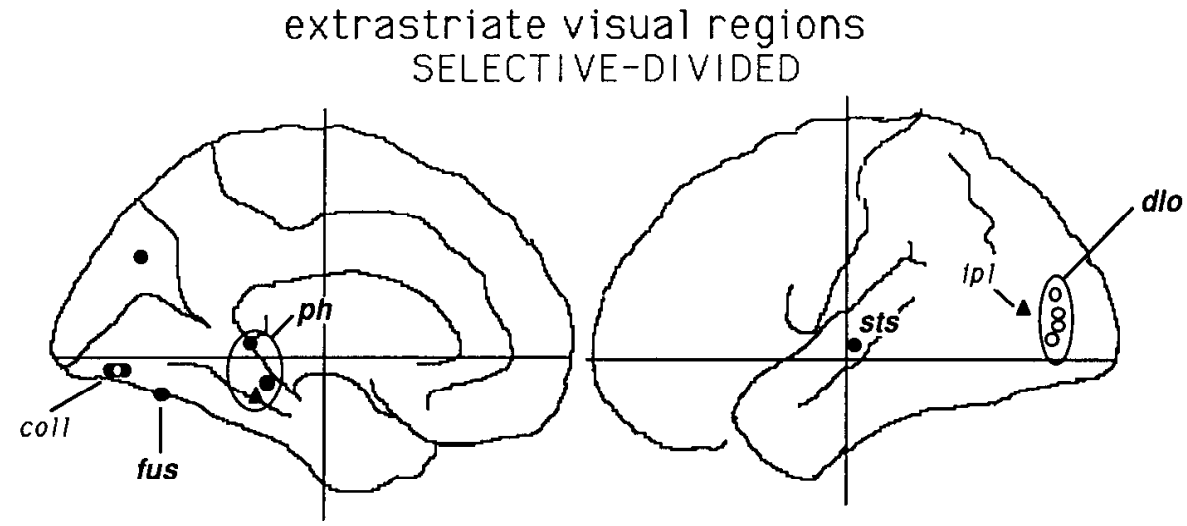

RIGHT
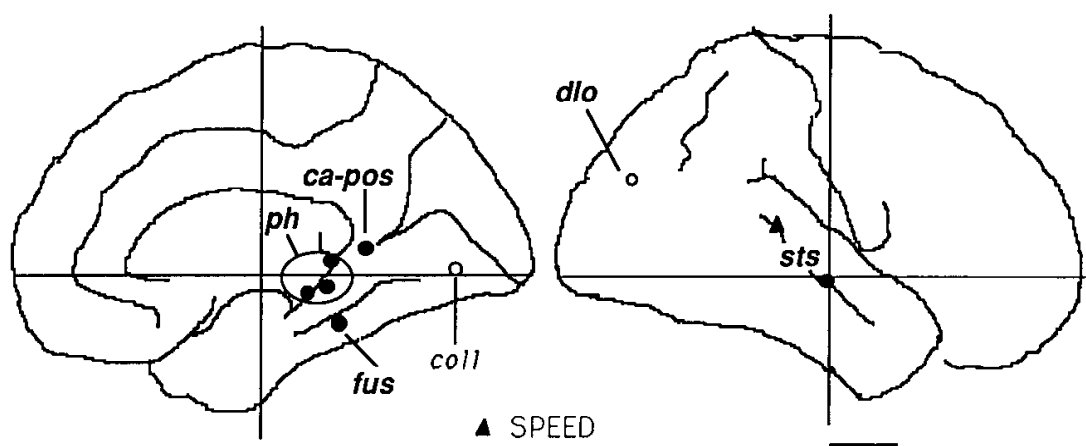

- COLOR

$\overline{20 \mathrm{~mm}}$

- SHAPE 
Table 3. Foci of activations in extrastriate visual cortex (see Table 2 notes for details)

\begin{tabular}{|c|c|c|c|c|c|}
\hline \multirow{2}{*}{ Focus/area } & & \multicolumn{3}{|c|}{ Coordinates } & \multirow[b]{2}{*}{ Magnitude } \\
\hline & & $\mathrm{S} / \mathrm{I}$ & $\mathbf{L} / \mathbf{R}$ & $\mathrm{A} / \mathrm{P}$ & \\
\hline \multicolumn{6}{|l|}{ Passive-fixation point } \\
\hline 14. Fusiform gyrus & $\mathbf{R}$ & -10 & -43 & -51 & 43 \\
\hline \multicolumn{6}{|l|}{ Speed-passive } \\
\hline 15. Lateral occipital gyrus & $\mathbf{L}$ & 2 & 41 & -47 & 32 \\
\hline 16. Lateral occipital gyrus & & 8 & 43 & -37 & 29 \\
\hline 17. Lateral occipital gyrus & $\mathbf{R}$ & 2 & -37 & -63 & 32 \\
\hline 18. Lateral occipital gyrus & & 0 & -33 & -45 & 29 \\
\hline 19. Inferior parietal lobe & $\mathrm{L}$ & 16 & 33 & -51 & 30 \\
\hline \multicolumn{6}{|l|}{ Speed-divided } \\
\hline 20. Inferior parietal lobe & $\mathbf{L}$ & 16 & 43 & -56 & $32^{*}$ \\
\hline 21. Superior temporal sulcus & $\mathbf{R}$ & 16 & -59 & -17 & $29^{*}$ \\
\hline 22. Parahippocampal gyrus & $\mathbf{L}$ & -12 & 23 & -23 & 29 \\
\hline \multicolumn{6}{|l|}{ Color-passive } \\
\hline 23. Collateral sulcus & $\mathrm{L}$ & 0 & 27 & -39 & $39 *$ \\
\hline 24. Dorsolateral occipital cortex & $\overline{\mathrm{L}}$ & 18 & 23 & -65 & 33 \\
\hline \multicolumn{6}{|l|}{ Color-divided } \\
\hline 25. Collateral sulcus & $\mathrm{L}$ & -4 & 27 & -65 & $39 *$ \\
\hline 26. Collateral sulcus & $\mathbf{R}$ & 2 & -21 & -61 & 30 \\
\hline 27. Dorsolateral occipital cortex & $\mathbf{L}$ & 6 & 29 & -65 & $35^{*}$ \\
\hline 27a. Dorsolateral occipital cortex & & 10 & 27 & -67 & $34^{*}$ \\
\hline 27b. Dorsolateral occipital cortex & & 14 & 25 & -67 & 33 \\
\hline 27c. Dorsolateral occipital cortex & & 20 & 23 & -66 & 31 \\
\hline 28. Dorsolateral occipital cortex & $\mathbf{R}$ & 30 & -25 & -62 & 30 \\
\hline \multicolumn{6}{|l|}{ Shape-passive } \\
\hline 29. Collateral sulcus & $\mathrm{L}$ & 0 & 19 & -55 & $54^{* *}$ \\
\hline 29a. Collateral sulcus & & -4 & 19 & -57 & $53^{* *}$ \\
\hline 30. Fusiform gyrus & $\mathrm{L}$ & -14 & 19 & -29 & $43^{* *}$ \\
\hline 31. Fusiform gyrus & $\mathbf{R}$ & -10 & -39 & -35 & $46^{* *}$ \\
\hline 32. Parahippocampal gyrus & $\mathbf{L}$ & -4 & 15 & -29 & $42^{* *}$ \\
\hline 33. Parahippocampal gyrus & $\mathbf{R}$ & -6 & -31 & -19 & $46^{* *}$ \\
\hline \multicolumn{6}{|l|}{ 34. Calcarine/parieto- } \\
\hline 35. Superior temporal sulcus & $\begin{array}{l}\mathrm{R} \\
\mathrm{R}\end{array}$ & $\begin{array}{l}0 \\
8\end{array}$ & $\begin{array}{l}-11 \\
-43\end{array}$ & $\begin{array}{l}-53 \\
-11\end{array}$ & $38^{*}$ \\
\hline \multicolumn{6}{|l|}{ Shape-divided } \\
\hline 36. Collateral sulcus & $\mathrm{L}$ & -4 & 29 & -67 & $29 *$ \\
\hline 36a. Collateral sulcus & & -4 & 25 & -63 & $28^{*}$ \\
\hline 37. Fusiform gyrus & $\mathbf{L}$ & -12 & 45 & -51 & $32^{* *}$ \\
\hline Fusiform gyrus & $\mathbf{R}$ & -14 & -27 & -25 & 25 \\
\hline Parahippocampal gyrus & $\mathrm{L}$ & 4 & 17 & -23 & $31^{* *}$ \\
\hline Parahippocampal gyrus & $\overline{\mathbf{R}}$ & -4 & -21 & -21 & $33^{* *}$ \\
\hline Parahippocampal gyrus & & 4 & -17 & -19 & $29^{*}$ \\
\hline 42. Parahippocampal gyrus & & -6 & -33 & -15 & 27 \\
\hline \multirow{2}{*}{$\begin{array}{l}\text { 43. Calcarine/parieto- } \\
\text { occipital sulcus }\end{array}$} & & & & & \\
\hline & $\mathbf{R}$ & 8 & -17 & -33 & $33^{* *}$ \\
\hline Superior temporal sulcus & $\mathbf{L}$ & 4 & 53 & -3 & $26^{*}$ \\
\hline 45. Superior temporal sulcus & $\mathbf{R}$ & -2 & -55 & -1 & $39^{* *}$ \\
\hline 46. Parieto-occipital cortex & $\mathbf{L}$ & 30 & 19 & -59 & $33^{* *}$ \\
\hline \multicolumn{6}{|l|}{ Divided-passive } \\
\hline 47. Collateral sulcus & $\mathbf{L}$ & -2 & 29 & -47 & 30 \\
\hline 48. Lateral occipital gyrus & $\mathbf{L}$ & 6 & 49 & -45 & $35^{*}$ \\
\hline
\end{tabular}

\section{Active-passive}

Attention to speed. A set of areas was modulated by attending to speed (Table 3, Fig. 5). Responses were localized on the lateral surface of the occipital gyri, two foci on the left, and two foci on the right. A fourth focus was detected on the left side deep in the inferior parietal lobule (between the fundus of the intraparietal sulcus and the angular gyrus).

Attention to color. When attending to color, foci were found in the left collateral sulcus between lingual and fusiform gyri and in left dorsolateral occipital cortex (Table 3, Fig. 5). The location of this latter response did not overlap the location of responses activated by speed.
Attention to shape. Five different regions were activated by attending to shape (Table 3, Fig. 5). Foci of activation were localized in the left collateral sulcus, and bilaterally in fusiform and parahippocampal gyri. A fourth region was found on the medial side at the intersection between calcarine sulcus and parieto-occipital sulcus, on the right side. The last active region was localized midway along the superior temporal sulcus in right temporal cortex.

Divided attention. Two significant responses were located in the left collateral sulcus and left lateral occipital gyrus (Table 3, Fig. 5), matching, respectively, the location of regions activated by attending to color (focus 23) and speed (focus 15). 


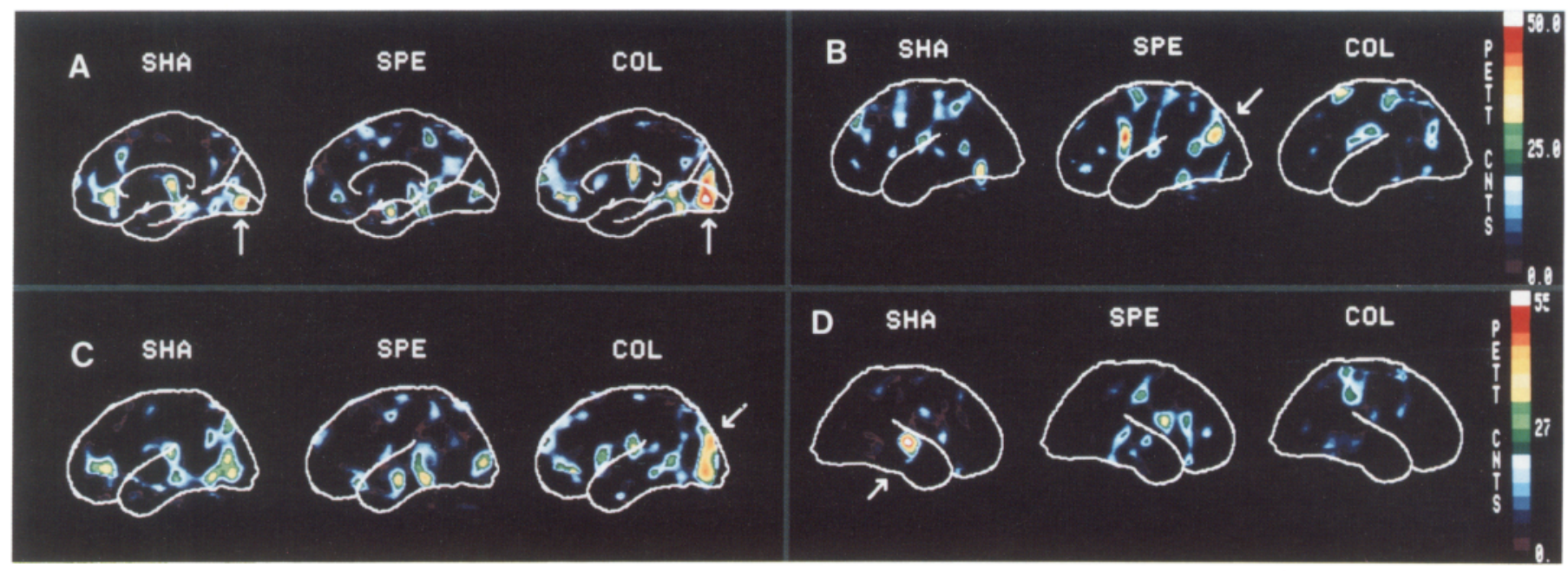

Figure 7. Sagittal blood-flow PET images for shape ( $S H A)$, speed $(S P E)$, and color $(C O L)$ conditions minus divided condition, plotted on outlines of the brain. $A$, Left collateral sulcus activation for attention to shape and color (slice taken $27 \mathrm{~mm}$ left of the midline). $B$, Left intraparietal sulcus activation for attention to speed (slice taken $44 \mathrm{~mm}$ left of the midline). $C$, Left dorsolateral occipital cortex activation for attention to color (slice taken $29 \mathrm{~mm}$ left of the midline). $D$, Right superior temporal sulcus activation for attention to shape (slice taken $54 \mathrm{~mm}$ right of the midline).

\section{Selective-divided}

Attention to speed. Using the divided-attention scan as control, only the left response in the inferior parietal lobule remained significant (Table 3, Figs. 6, 7B). Activations on the lateral occipital gyri fell to the noise level. Two new foci were detected in the left parahippocampal gyrus and in the right superior temporal sulcus. The latter response was distinct from the right superior temporal sulcus response obtained in the shape condition.

Attention to color. The same regions as in the passive-scan subtraction were active. In the collateral sulcus, significant responses were obtained bilaterally, though they were still stronger on the left side. The focus on the left (focus 25) was in a similar location to the responses found in both shape-passive (focus 29) and shape-divided (focus 36) subtractions (Table 3, Figs. 6 , $7 \mathrm{~A}$ ). Bilateral foci in dorsolateral occipital cortex were also significantly active (Table 3, Figs. 6, 7C). The extent of activated cortex was larger on the left than on the right, and extended more ventrally. These dorsolateral occipital regions did not overlap in location with regions modulated by attention to shape or speed.

Attention to shape. The five regions (left collateral sulcus, bilateral fusiform and parahippocampal gyri, right intersection of calcarine and parieto-occipital sulcus, and right superior temporal sulcus) activated when subtracting the passive-task scan were still significantly active after subtracting the divided-attention scan. In this subtraction, the superior temporal sulcus activation was bilateral, but the magnitude of this activation was still stronger on the right side, consistent with the right lateralization found in the passive subtraction (Table 3, Figs. 6, $7 D$ ). An additional focus, located in left parieto-occipital cortex, was also detected.

In some of these regions, such as the collateral sulcus (focus 29 vs. 36a) and the fusiform gyrus (focus 31 vs. 38), the magnitude of blood-flow response decreased in this subtraction in comparison to the passive subtraction. In other regions, such as the right superior temporal sulcus (focus 35 vs. 45 ), the magnitude of the response was not modified. Similar effects on mag- nitude were seen for attention to speed and color (see Discussion).

In summary, different portions of extrastriate visual cortex were activated when subjects attended to different features of the same set of visual stimuli. While in some regions the magnitude of the blood-flow response was decreased by the subtraction with the divided-attention scan, in other regions the magnitude was unchanged. The divided-attention condition activated many fewer regions than the selective conditions.

\section{Extravisual regions}

Passive-fixation point

One focus in primary motor cortex (coordinates: $S / I=45, L / R$ $=-43, \mathrm{~A} / \mathrm{P}=-7$ ) was detected on the right side. All subjects used the left hand to respond by key press.

\section{Active-passive}

Divided attention. Four cortical regions were active outside visual cortex when the divided-attention condition was subtracted from the passive condition (Table 4, Fig. 8). Two responses were localized in the medial portion of the frontal lobe in the anterior cingulate region (Fig. 9). Two other responses were localized in right prefrontal cortex and beneath the supramarginal gyrus.

Attention to shape, speed, and color. Anatomical regions activated in the three selective conditions by this subtraction are shown in Table 4 . The only region commonly activated across selective conditions was the left globus pallidus.

\section{Selective-divided}

Attention to shape, speed, and color. Anatomical regions active across all selective conditions are shown in Table 4 . In comparison to the subtraction with the passive task, several regions were commonly active across conditions.

Regions common to all selective conditions included left globus pallidus, right head of the caudate nucleus, left inferior premotor cortex, right insular cortex, and right posterior thalamus/superior colliculus (Table 4, Fig. 10). The magnitude of 

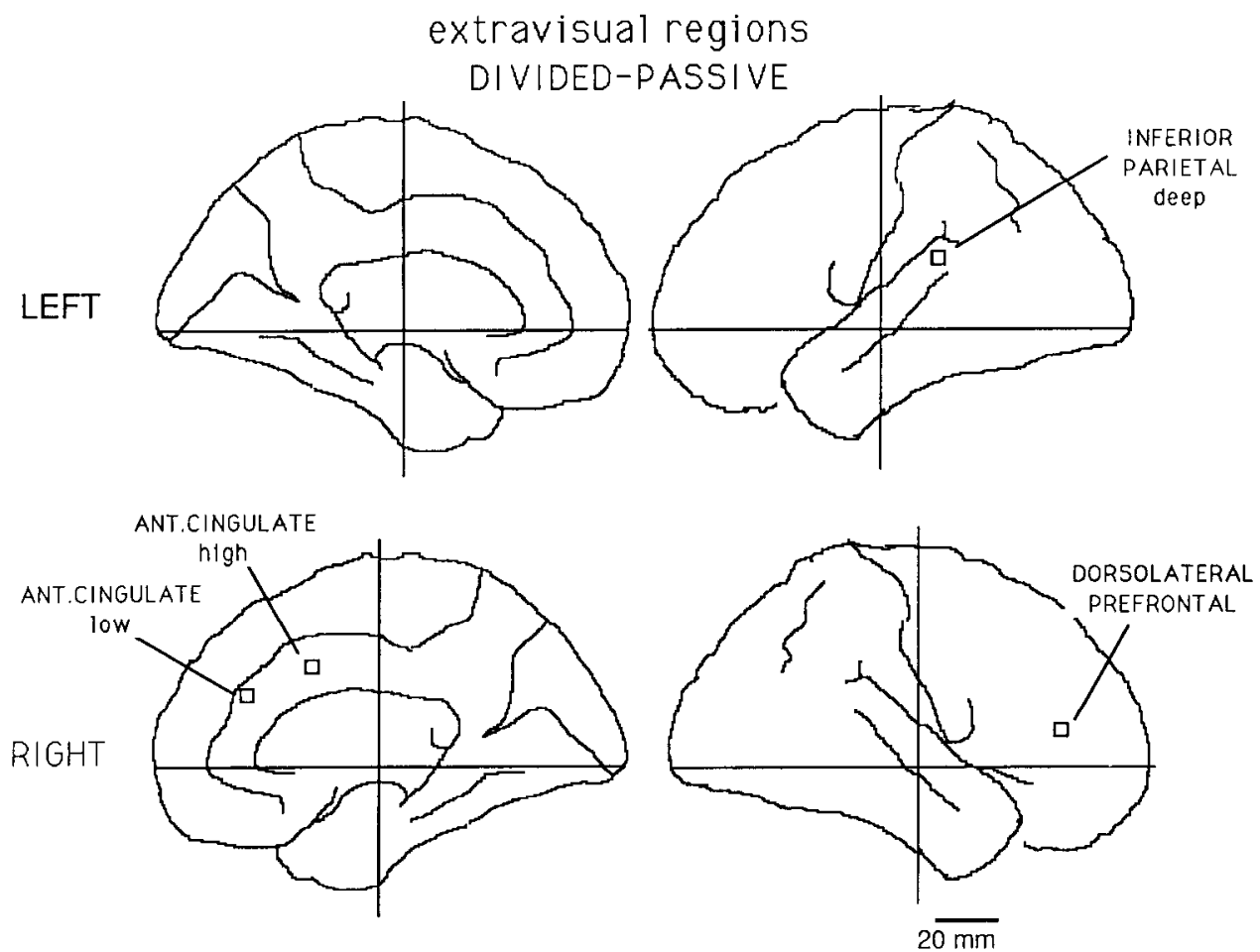

Figure 8. Outline of blood-flow activations in extravisual regions: dividedpassive. the response in the globus pallidus (focus 60) was unchanged from the passive subtraction (focus 53).

Most of these regions were raised above the noise level when using the divided-attention scan as control. Therefore, these areas were relatively hypoperfused in the divided-attention condition compared to the passive task.
In this experiment there are other examples of activations that reach statistical significance when the divided attention is subtracted from each selective condition, and not when the passive task is subtracted away. In our general experience, differences in magnitude for a given response when going from a simple subtraction (between one active and one passive con-

Table 4. Foci of activations in extravisual brain regions

$\begin{array}{lll}\text { Divided } & \text { Speed } & \text { Color }\end{array}$

\begin{tabular}{|c|c|c|c|c|c|}
\hline \multicolumn{6}{|l|}{ Active-passive } \\
\hline 49. Anterior cingulate, high & $\mathbf{R}$ & $34,-7,23(40)^{* *}$ & & & \\
\hline 50. Anterior cingulate, low & $\mathbf{R}$ & $24,-11,45(28)$ & & & \\
\hline 51. Dorsolateral prefrontal cortex & $\mathbf{R}$ & $12,-45,49(39)^{* *}$ & & & \\
\hline 52. Supramarginal gyrus & $\mathrm{L}$ & $24,33,-20(28)$ & & & \\
\hline 53. Globus pallidus & $\mathrm{L}$ & & $8,17,9(38)^{* *}$ & $4,19,15(35)^{*}$ & $2,5,11(27)^{\mathrm{Ns}}$ \\
\hline 54. Thalamus & $\mathbf{R}$ & & $10,-17,1(33)$ & & $6,-13,1(31)$ \\
\hline 55. Superior colliculus & $\mathbf{R}$ & & & & $0,-3,-13(31)$ \\
\hline 56. Nucleus caudatus head & $\mathbf{R}$ & & $8,-19,41(41)^{* *}$ & & \\
\hline 57. Nucleus caudatus head & $\mathbf{L}$ & & & $12,11,13(40)^{* *}$ & \\
\hline 58. Insular cortex & $\mathbf{R}$ & & $18,-35,15(30)$ & & \\
\hline 59. Inferior premotor cortex & $\mathbf{L}$ & & $26,49,15(39)^{* *}$ & & \\
\hline Selective-divided & & & & & \\
\hline 60. Globus pallidus & $\mathbf{L}$ & & $8,17,9(34)^{*}$ & $6,19,17(35)^{* *}$ & $-2,13,13(32)^{* *}$ \\
\hline $\begin{array}{l}\text { 61. Nucleus caudatus head, } \\
\text { medial }\end{array}$ & $\mathbf{P}$ & & & $10-115(42)^{* *}$ & \\
\hline 62. Inferior premotor cortex & L & & $18,47,17(35)^{* *}$ & $14,49,7(33)$ & $26,53,25(30)^{*}$ \\
\hline 63. Insular cortex & $\mathbf{R}$ & & $0,-35,9(37)^{* *}$ & $4,-41,11(42)^{* *}$ & $-4,-32,8(23)$ \\
\hline $\begin{array}{l}\text { 64. Posterior thalamus/ } \\
\text { superior colliculus }\end{array}$ & $\mathbf{R}$ & & $4,-5,-21(40)^{* *}$ & $-2,-5,-25(37)^{*}$ & $8,-7,-11(33)^{*}$ \\
\hline 65. Lateral orbitofrontal cortex & $\mathrm{L}$ & & $-14,19,29(32)^{*}$ & & $0,27,39(28)$ \\
\hline 66. Thalamus & $\mathbf{R}$ & & & & $12,-11,-1(38)^{* *}$ \\
\hline $\begin{array}{l}\text { 67. Nucleus caudatus head, } \\
\text { lateral }\end{array}$ & $\mathbf{L}$ & & $26,11,17(35)^{* *}$ & & $26,15,15(35)^{*}$ \\
\hline $\begin{array}{l}\text { 68. Nucleus caudatus head, } \\
\text { lateral }\end{array}$ & $\mathbf{R}$ & & & $18,-21,27(39)^{*}$ & \\
\hline
\end{tabular}




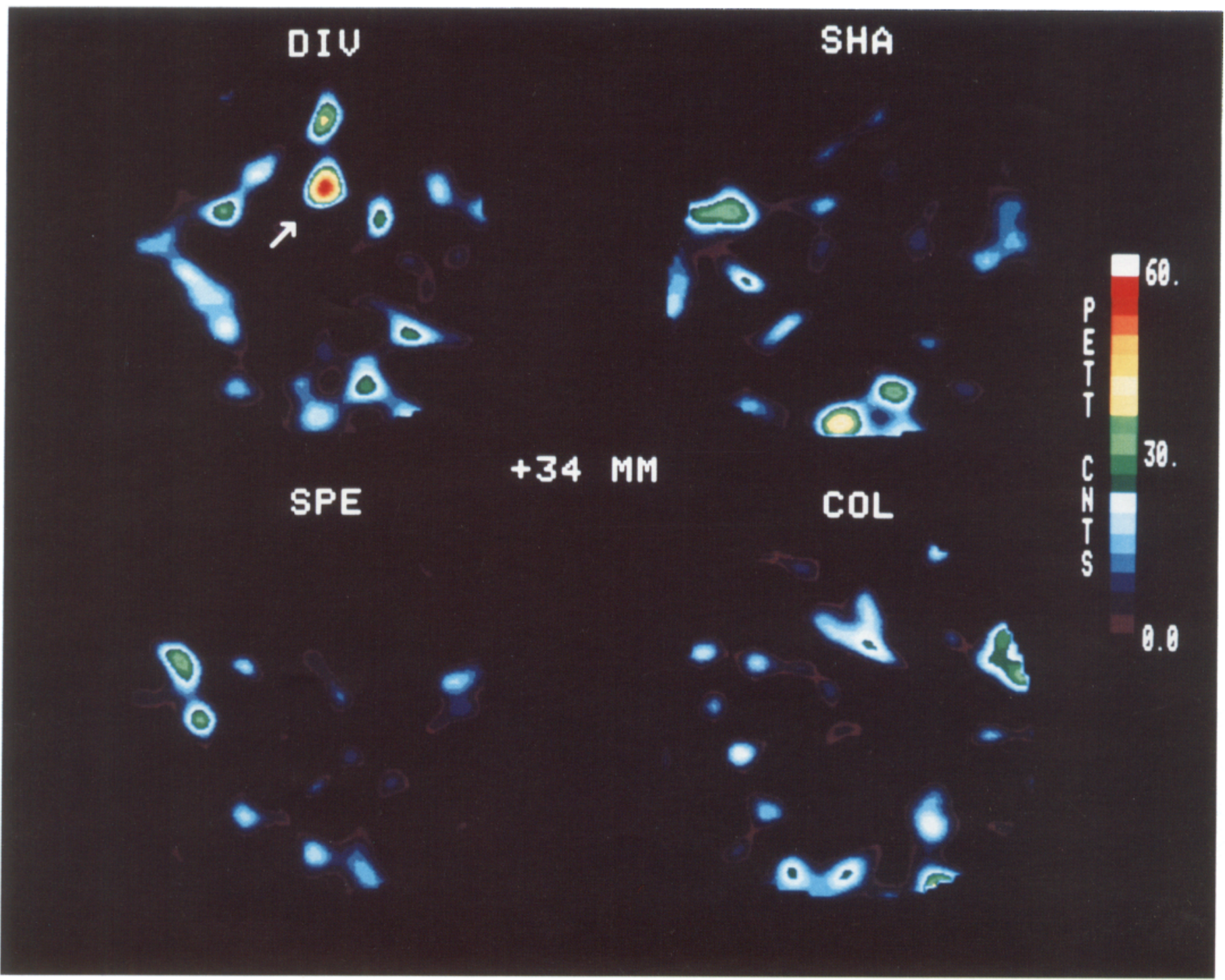

Figure 9. Horizontal blood-flow PET image for divided (DIV), shape (SHA), speed (SPE), and color (COL) conditions minus passive condition taken $34 \mathrm{~mm}$ above the reference plane through the anterior and posterior commissures. Anterior cingulate cortex activated only in the divided condition.

dition, e.g., selective-passive) to a complex subtraction (between two active conditions, e.g., selective-divided) can be explained by physiological or methodological factors.

(1) Physiological factors. In relationship to a passive baseline, the same region may show a small positive response in one active condition and a small negative response in another active condition. Neither focus might be significant when compared to the passive condition, but will be significant in the subtraction between the two active tasks. This effect may apply to responses in extrastriate cortex or extravisual areas that are significant in selective-divided and not in selective-passive subtraction.

(2) Methodological factors: masking of a low-level response by a high-level response. Large blood flow responses can produce either "spatial" or "statistical" masking on lower level responses. When two foci are adjacent, the computerized search algorithm, which records magnitude and location of each peak in the image before the performance of the statistical analysis, may only detect the stronger response (spatial masking).

The presence of a high-level response may also mask low- level foci through the normalization procedure, which is adopted to negate global blood-flow fluctuations across scans, and through the calculation of the post hoc $Z$ scores, which estimate the statistical significance of a response (statistical masking).

\section{Discussion}

Visual tasks involving threshold changes of stimulus color, speed, and shape were used to study the influence of selective attention on feature discrimination.

In a first experiment, the effects of attention were assessed psychophysically. The sensitivity to change in a single feature, for example, a slight color variation, was higher when attention was focused on that feature than when attention was divided among several features. The sensitivity advantage was similar in magnitude (about $0.9 d^{\prime}$ units) for color, speed, and shape discriminations. Furthermore, in the selective conditions, the sensitivity of these discriminations was not affected by simultaneous changes in unattended features.

In a second experiment, the functional anatomy of these at- 


\section{EXTRAVISUAL REGIONS SELECTIVE - DIVIDED}

Figure 10. Outline of blood-flow activations in extravisual regions. Selective-divided. Left, Coronal section taken $12 \mathrm{~mm}$ anterior to the origin of the anatomical stereotactic space. Right, left lateral hemisphere. tentional effects was traced using PET activation methodology. Four principal results were obtained.

(1) Activation was seen at or near primary visual cortex in all active conditions compared to passive presentation of identical sets of visual stimuli.

(2) A set of areas in extrastriate visual cortex was specifically activated by each of the selective conditions. These activations represent enhancements of neuronal activity above a passive or a divided-attention baseline. For shape, they were localized in the collateral sulcus, fusiform and parahippocampal gyri, the calcarine/parieto-occipital sulcus intersection, and in temporal cortex along the superior temporal sulcus. For speed, the enhanced region was localized deep in the inferior parietal lobule. For color, they were localized in both collateral sulcus and dorsolateral occipital cortex. In contrast, little activation was found in extrastriate cortex in the divided-attention condition compared to a passive control.

(3) There was a set of areas outside the visual system (globus pallidus, caudate nucleus, posterior thalamus/colliculus, inferior premotor cortex, insular cortex, and lateral orbitofrontal cortex) that was active in the selective-attention tasks when compared to the divided-attention task.

(4) Conversely, there was another set of areas outside the visual system (anterior cingulate, right prefrontal cortex) that was active in the divided-attention condition, but not in any of the selective conditions.

\section{Psychophysical observations}

The results of our psychophysical experiments show that focusing attention on a stimulus feature enhanced sensitivity compared to conditions in which attention was divided across several stimulus features. Bccause perceptual difficulty and motor output were equated across conditions, differences in sensitivity must depend on the different number of features that subjects were attending to in the selective and divided conditions.

Selection by visual features is commonly believed to be less efficient than selection by spatial location (Allport, 1989). Earlier psychological reports failed to find consistent attentional effects on suprathreshold discriminations (Egeth, 1966, 1967; Lappin, 1967; Hawkins, 1969; Treisman, 1969). However, attentional effects appear to be more easily demonstrated by increasing the perceptual difficulty of the task, or target-nontarget similarity (Duncan and Humphreys, 1989). Results qualitatively similar to ours have been reported by Vogel et al. (1988), who also studied near-threshold discriminations. They compared the accuracy for discriminating the orientation and spatial frequency of gratings when subjects were cued to one of the attributes either before or after stimulus presentation. Higher thresholds were found in the post-cueing condition than in the pre-cueing condition. The selective- and divided-attention conditions of our paradigm were qualitatively similar to the pre- and postcueing conditions, respectively. In the divided and post-cueing conditions, multiple attributes had to be monitored in order to detect a stimulus change, while in the selective and pre-cueing conditions, discriminations could be based on the selected attribute.

There was a high degree of efficiency in filtering out irrelevant information. Sensitivity did not decrease as a function of the number of unattended attributes changed in a trial. The filtering of unattended information was not complete, however, because subjects were more prone to perceive a stimulus change (resulting in either a hit or a false alarm) when more unattended changes were presented in a trial.

These psychophysical results do not identify the contributions that different putative attentional mechanisms might make to the performance of our tasks. The perceptual advantage in the selective conditions might represent a form of sensory enhancement in the visual channels processing the attended information, or a decrease in the quality of the signal delivered by each unattended pathway (filtering). The attentional manipulation may also affect decision mechanisms. In the selective condition, subjects can ignore activity from irrelevant sensory channels, decreasing the number of noise-generated false alarms. This decrease will produce a $d^{\prime}$ advantage over the divided condition. Finally, memory processes might also be implicated. In the selective condition, subjects must retain information concerning a single attribute during the 200 -msec interval between frames, while in the divided condition they must retain information about all three attributes.

\section{Functional anatomy by PET}

Two control conditions were used as baseline for each selective condition. The condition involving passive presentation of the 
visual stimulus arrays and alternating key presses was subtracted from each of the four active conditions (three selective conditions and the divided-attention condition). Although active and passive conditions were matched for visual sensory and overall motor activity, task difficulty and behavioral states were clearly different. This difference may produce a general increase in responsiveness due to arousal or an increase confined to the visual system due to engagement in a visual task. In a second set of subtractions, the divided-attention condition was subtracted from each of the selective conditions. In this case, the activations probably reflect feature-specific effects. A decrease in the magnitude of responses in the selective conditions from the passive to the divided subtraction probably indicates that those responses reflect a contribution from both nonspecific and featurespecific effects.

\section{Early visual regions}

Primary and surrounding extraprimary visual cortex (e.g., area 17 and lingual gyrus) was more active in the active than in the passive tasks and either dropped to the noise level or decreased the magnitude of their response when the divided condition was subtracted from each selective condition. This decrement in activity is probably related to the difference in behavioral state between active and passive conditions. Effects of behavioral state on neuronal firing have been reported in single-unit studies in several visual areas, including V1, V2 (Wurtz and Mohler, 1976; Robinson et al., 1980; Wurtz et al., 1980; Livingstone and Hubel, 1981; Schroeder et al., 1989), V4, and posterior parietal region PG (Motter and Mountcastle, 1981; Mountcastle et al., 1987). However, we cannot exclude the presence of feature-selective modulations in area 17 (or within its anatomophysiological subdivisions; Lund, 1973) as suggested by the residual activation for shape and speed minus divided attention. Some selective effects on neuronal firing have been described during single-unit recording from V1 neurons (Haenny and Schiller, 1988).

\section{Extrastriate visual regions}

Some regions in extrastriate cortex showed changes similar to those in area 17 (i.e., a probable contribution from both specific and nonspecific factors). Examples include collateral sulcus and fusiform and parahippocampal gyri activations.

Other extrastriate regions, presumably farther from primary visual cortex (e.g., superior temporal sulcus for shape, inferior parietal lobule for speed, and dorsolateral occipital cortex for color), showed changes in activation that are most easily interpreted as purely selective effects. The activations were represented by positive blood-flow change at one or a group of locations specific for a particular feature and whose magnitude was similar in both passive and divided subtraction.

We will argue in the following subsections that these changes in activity occurred in regions of extrastriate cortex that are specialized for processing the attended visual feature.

\section{Attention to speed}

Attending to speed consistently activated a region of the left inferior parietal lobule deeply positioned between the intraparietal sulcus and the angular gyrus.

Studies in monkeys have implicated regions of the posterior parietotemporal cortex in visual motion analysis, including areas MT and MST in the superior temporal sulcus of macaques. Neurons in area MT appear to process visual motion infor- mation (Dubner and Zeki, 1971; Maunsell and Newsome, 1987) and are relatively unaffected by attentional manipulations (Newsome and Wurtz, 1981; Wurtz et al., 1984). Neurons in an adjacent area, MST, are also responsive to moving visual stimuli (Komatsu and Wurtz, 1988a,b). However, neurons in MST also show signals related to smooth-pursuit tracking, as well as neuronal enhancement of a visual response when the moving target is used for pursuit initiation (Newsome et al., 1988).

Previous PET activation studies have shown that regions in the inferior parietal lobule can be activated by stimuli or tasks known to drive neurons of the motion system in macaques. Miezin and colleagues (Miezin et al., 1987, F. M. Miezin et al., 1988; Zeki et al., 1991) have found an area activated by the presentation of low-contrast dots moving in different directions, or by high-temporal-frequency stimuli. A nearby dorsal region within the intraparietal sulcus was activated during a visually guided smooth-pursuit tracking task (F. Miezin et al., 1988). The latter response was bilateral, stronger on the left side, and adjacent to, but possibly distinct in location from, the visual motion region. Recently, PET activation within the intraparietal sulcus during visually guided smooth-pursuit tracking tasks has been also reported by another group of investigators (Colby and Zeffiro, 1990). These areas are similar in location to those found in lesion studies that produce selective motion perception and pursuit deficits (Zihl et al., 1983; Thurston et al., 1988).

The inferior parietal lobule activation described in the present study for attention to speed cannot be conclusively identified with one or the other of the cortical regions activated in previous motion experiments (F. M. Miezin et al., 1987, 1988; F. Miezin et al., 1988), because they were obtained in a different group of subjects. Its location, however, was more similar to the region activated during the smooth-pursuit task. ${ }^{4}$

The qualitative similaritics between our results and those found in single-unit studies in monkeys suggest that the two activations in humans may be homologous to areas MT and MST in macaque monkeys. The results also provide evidence that the selective modulation seen in extrastriate visual cortex is an enhancement of the attended information, in this case an enhancement of an MST-like region during speed discrimination, rather than a filtering or inhibition of the unattended channels.

\section{Attention to color}

Two cortical regions were activated by attending to color. $\mathrm{Bi}$ lateral activations were obtained in the collateral sulcus between lingual and fusiform gyri and in dorsolateral occipital cortex, and both responses were stronger on the left side.

The collateral sulcus response overlapped a similar activation obtained during shape discrimination. The location of this response is also similar to that found in a recent PET study (Lueck et al., 1989), in which subjects were passively presented with colored Mondrian stimuli (Land, 1974) and equiluminant gray stimuli were used as a control. In humans, selective deficits for color discrimination (achromatopsia) have been correlated with

\footnotetext{
${ }^{4}$ The similarity of response location for "smooth pursuit" (F. Miezin, 1988) and the "attention"-modulated response raises the possibility that undetected small-amplitude tracking eye movements were responsible for the activation. This seems unlikely for the following reasons: there was no evidence of activation in the MSI-like region for any of the other active conditions (shape, color, divided); larger-amplitude smooth-pursuit eye movements might be expected for shape, color, and the divided condition, because such tasks rely more on foveal vision than does a discrimination involving motion of the array, and this expectation is met; more eye movements were recorded during shape, color, and divided tasks than during speed tasks, though in all conditions eye movements were minimal.
} 
damage to lingual and fusiform gyri (Meadows, 1974b; Damasio et al., 1980), with a distribution similar to our PET response. These results again argue that the attentional modulation we see in the collateral sulcus occurs in a region processing information about the attended attribute.

In our study, the collateral sulcus activation was enhanced for both color and shape discrimination. V4, an area early in the monkey extrastriate hierarchy, also appears to process information about both the color and the form of visual stimuli. Although it was originally believed to be a color-processing area (Zeki, 1973), single-unit recording studies have demonstrated that V4 neurons are tuned for both chromatic and spatial (bars, spatial frequency) information (Desimone et al., 1985; Desimone and Schein, 1987). Furthermore, bilateral ablations of V4 in monkey elevate thresholds for hue and impair pattern and face recognition (Heywood and Cowey, 1987). This area is also reported to show modulation when attention is directed to these attributes. Feature-selective extraretinal enhancement of neuronal activity and sharpening of tuning curves have been reported in neurons in monkey V4 during color and orientation discriminations (Haenny and Schiller, 1988; Spitzer et al., 1988).

The common response for color and shape attention in the collateral sulcus may represent a processing region in humans that is functionally similar to monkey V4. Recently, a study on callosal connections in humans (Clark and Miklossy, 1990) has tentatively localized on the lingual gyrus the border between area V2 and ventral posterior area VP, and in the collateral sulcus the border between VP and V4.

The response in dorsolateral occipital cortex may represent a further stage for color processing beyond the collateral sulcus. In macaque, $\mathrm{V} 4$ is now thought to represent a complex of distinct visual areas (Van Essen, 1985) extending from area V2 to area MT in the temporal lobe. It is possible that the dorsolateral response, seen only during color attention, is a part of the V4 complex (Van Essen and Zeki, 1978; Schein et al., 1982; Maguire and Baizer, 1984; Van Essen, 1985). The unique aspect of this region in our study is that it is only affected by attention to color, and not by attention to either of the other attributes.

\section{Attention to shape}

A complex network of extrastriate visual areas was enhanced when discriminating changes in shape. Activations were localized in the collateral sulcus (the same region as during color attention), in fusiform and parahippocampal gyri, and in temporal cortex along the superior temporal sulcus. The activation in temporal cortex was stronger in the right than in the left hemisphere.

Most activations were localized ventrally in the occipital and temporal lobes. In a coarse way, the ventral distribution is similar to the occipitotemporal system in monkeys that is thought to be specialized for object recognition and discrimination in monkeys (Ungerleider and Mishkin, 1982; Ungerleider, 1985).

The association of the ventral posterior cortex with objectprocessing operations is supported by lesion behavior studies in both humans and macaques. The lingual, fusiform, and parahippocampal gyri have been associated in humans with higherorder visual deficits such as object agnosia (the failure to recognize visual objects; Bauer and Rubens, 1985; Damasio, 1985) and prosopagnosia (the failure to recognize familiar faces; Bodamer, 1947; Meadows, 1974a; Damasio et al., 1982). Similar deficits have been reported in humans after right temporal lobectomy (Milner, 1968).
Inferotemporal cortex (IT) lesions in monkeys produce similar deficits in pattern discrimination or recognition tasks (Mishkin, 1966; Gross, 1973; Ungerleider and Mishkin, 1982; Mishkin et al., 1983). Recordings from single neurons in IT show sensitivity to a variety of simple and complex object stimuli (Gross et al., 1972; Schwartz et al., 1983; Desimone et al., 1984), and the neurons are selective to shapc descriptors that can be used to provide a global representation of surface contours or shape (Desimone et al., 1985).

\section{Concluding remarks on the visual system modulation}

Selective attention to a visual feature enhanced behavioral sensitivity over a divided-attention condition. Correspondingly, in the selective conditions, neuronal enhancement of visual regions putatively specialized for processing the selected feature was demonstrated with PET. These extrastriate visual regions are very likely a site or locus at which top-down modulatory signals can influence the processing of visual information.

Recent data from single-unit recording experiments in monkey suggest that both "set-related" (the encoding of a task instruction) and "matching" (the actual coincidence between the attended and the actual visual input) signals might account for the selective modulations reported in this study.

Selective blood-flow changes might be produced by signals related solely to task instruction. There is evidence that setrelated instructions can modulate neurons in monkey area V4. Haenny et al. (1988) found that the activity of over half of V4 neurons was different when the monkey was cued to look for different orientations. Such modulation was found both when the animal was instructed by a briefly presented visual cue and when instructed by a continuously presented tactile cue. The independence of the modulation from the modality of the instructing cue suggests that it was the symbolic meaning of the instruction, rather than the sensory signal, that modulated V4 neurons. In our task, instructions (e.g., attend to shape) delivered from higher-order centers might "prime" the appropriate visual pathways for shape processing.

A second signal that may produce these selective blood-flow changes is sensory enhancement, which may represent a correspondence between an internal set-related signal and an appropriate input signal (matching). In about $70 \%$ of V4 neurons, there is an increment in the response to visual stimuli and a sharpening of tuning functions when a monkey detects a target stimulus defined by a simple feature change in a match-tosample task (Haenny and Schiller, 1988). These feature-specific enhancement effects are stronger and more frequent for nearthreshold discriminations (Spitzer et al., 1988). If many neurons in one area show such matching-related enhancement, then selective changes in blood flow similar to those found in the present study might be expected.

Neuronal enhancement and sharpening of tuning curves may account for differences in psychophysical sensitivity between the selective- and divided-attention conditions. In "primed" pathways (set-related signal), the incoming visual information triggered stronger and more sclcctive ncuronal responses (higher signal-to-noise ratio) than in unprimed pathways. The resulting higher-quality transmission of attended information could lead to lower psychophysical thresholds.

\section{Extravisual areas}

Outside the visual system, one set of brain regions (globus pallidus, anteromedial caudate nucleus, inferior premotor cor- 
tex, insular cortex, posterior thalamus/superior colliculus, lateral orbitofrontal cortex) was commonly activated across the selective-attention tasks, and another set of areas (anterior cingulate cortex, dorsolateral prefrontal cortex, inferior parietal lobe) was activated in the divided-attention task. The two attentional sets, therefore, did not simply activate similar brain systems at different quantitative levels, but rather were treated by the brain as qualitatively distinct tasks.

In agreement with this interpretation, enhancement of extrastriate visual areas was seen primarily during the selective tasks, and reciprocal functional interactions were found between areas active in the selective tasks and areas active in the divided task. In particular, some regions activated by all the selective conditions, such as caudate, thalamus, low premotor cortex, insular cortex, and lateral orbitofrontal cortex, were relatively hypoperfused during the divided-attention condition, in comparison to the passive baseline.

A brief account of the operations underlying the differences between the divided and selective tasks and the neural regions that may implement those operations will be presented. Succeeding sections will consider in more detail the evidence underlying this admittedly speculative framework.

The selective task involves the adoption and maintenance of a set for a particular feature. This might be accomplished in a circuit connecting lateral orbitofrontal cortex and the basal ganglia. This set is then implemented in the visual system through the thalamus, which routes the activation to the appropriate extrastriate region. The match-to-sample task used in this study requires that information about the first frame be maintained in a memory and compared to the second frame. We suggest that, in the selective task, both set-related and matching signals occur in extrastriate cortex (see above). The results of that matching operation are then directed to insular cortex and inferior premotor cortex for response selection.

The divided task does not involve a preexisting set. However, the memory demands during the interframe interstimulus interval are much greater in the divided task than in the selective task. Additionally, information from different extrastriate areas needs to be coordinated and compared. We therefore suggest that the task-related and matching functions that are accomplished in extrastriate cortex in the selective task are partly implemented in lateral prefrontal cortex in the divided task. Response selection then occurs in the anterior cingulate region.

\section{Source of selective set}

The selective task requires the maintenance of information about the task-relevant feature. This short-term memory signal may be the source of the selection that eventually acts at the site of visual processing. It is possible that responses in anteromedial caudate, globus pallidus, and lateral orbitofrontal cortex represent activations within a "lateral orbitofrontal circuit," one of the anatomical cortico-basal ganglia loops.

Alexander and colleagues (Alexander et al., 1986) have proposed that connections between frontal cortex and basal ganglia can be conceptualized as a number of parallel, segregated, reentrant loops. Each loop connects a set of cortical areas with discrete parts of the striatum and the globus pallidus. The segregated basal ganglia output would then reenter one of the original cortical areas through a specific thalamic relay. It has been proposed that each loop might perform the same basic operation(s) within neural networks specialized for a different function (c.g., motor, oculomotor, memory processing).
Evidence for a relationship between fronto-basal activity and short-term memory comes both from physiological recordings in monkeys and from lesion studies in humans and monkeys. Activity of caudate and substantia nigra (pars reticulata) neurons is more affected during memory-contingent tasks than during sensory-dependent tasks (Hikosaka and Wurtz, 1983; Hikosaka et al., 1989b). A number of higher cognitive deficits, similar to those obtained after frontal lobe lesions, have been reported after damage to the basal ganglia (Taylor et al., 1986; Sagar et al., 1988; Saint-Cyr et al., 1988). A deficit of inhibition of return, a phenomenon related to spatial attention, has been reported after prefrontal cortex lesions (Henik et al., 1990), and this deficit disappears when a striatal lesion is added to the prefrontal damage.

Lesions of lateral orbitofrontal cortex impair performance in monkeys on a number of tasks requiring memory for visual features of objects (Passingham, 1972, 1975; Mishkin and Manning, 1978; Bachevalier and Mishkin, 1986). Moreover, neurons carrying signals related to a feature cue (e.g., a color) in the delay period of a match-to-sample task have been recorded in lateral orbitofrontal cortex (Rosenkilde et al., 1981).

\section{Selective top-down signals}

The selective set induces modulations in the different visual extrastriate cortical regions. An area that is activated across selective conditions localizes to the posterior thalamus/collicular region. A large part of the posterior thalamus, the pulvinar, is heavily connected with both prefrontal cortex (Asanuma et al., 1985; Andersen, 1987) and extrastriate visual cortical areas (Benevento and Rezak, 1976; Benevento and Davis, 1977; Chalupa, 1977; Bender, 1981).

The pulvinar is believed to be part of a system that directs visual attention in space (Petersen et al., 1985, 1987; Andersen, 1987; Posner and Petersen, 1990). In particular, the pulvinar has been hypothesized to be critical for "engaging" a location in space (Rafal and Posner, 1987) or for filtering out irrelevant information in the visual field (Desimone et al., 1989; LaBerge and Buchsbaum, 1990; Posner and Petersen, 1990). Metabolic pulvinar activation during visual discrimination tasks in cluttered fields has been reported in normal subjects (LaBerge and Buchsbaum, 1990). In monkey, inactivation of the lateral pulvinar (Desimone et al., 1989) impairs object recognition at a location only when distractors are simultaneously present in the visual field.

Neural responsiveness in occipitotemporal area V4 and area IT is gated by the position of spatial attention in the visual field (Moran and Desimone, 1985), and inactivation of the lateral pulvinar impairs a monkey's ability to focus attention during an object recognition task (Desimone et al., 1989). Areas V4 and IT are thus considered the "recipient" or the "site" of spatial selectivity generated in posterior parietal cortex and funneled to these areas through the pulvinar.

The attentional effect we have described is not spatial in nature, but rather is related to the selection of a visual feature. The pulvinar, involved in "engaging" and "filtering" operations in visual spatial attention, might also implement the selection of a visual feature. Activity in areas V4 and IT, which serve as the site of a spatial selection signal controlled by the pulvinar, is also modulated by feature-specific sets (Braitman, 1984; Richmond and Sato, 1987; Haenny and Schiller, 1988; Haenny et al., 1988; Spitzer et al., 1988). Additionally, the selective task in the present study requires that information from unattended 
feature changes be discarded, similar to the distractor conditions in the spatial tasks under which the pulvinar is most active (Desimone et al., 1989; LaBerge and Buchsbaum, 1990). Finally, the extensive connections between the pulvinar and extrastriate cortex make it a plausible candidate for mediating the selective sets reported here. This top-down (from attentional to sensory regions) signal may be a facilitatory "prime" on the visual regions processing the attended feature.

\section{Complex processing and visual short-term memory demands}

There are two related demands that may encourage right prefrontal processing in the divided-attention condition. In the divided condition, more information than in the selective condition has to be stored between the first and second frame. Additionally, the storage must involve information from different extrastriate regions. This requirement might be reflected in activity in brain regions that store more complete representations of visual scenes.

Prefrontal cortex receives input from both occipitoparietal and occipitotemporal visual areas (Jones and Powell, 1970; Jacobsen and Trojanowski, 1977; Seltzer and Pandya, 1984). Ablations of this region disrupt a variety of tasks (e.g., delayed response, alternation, or matching-to-sample tasks) in which complex visual information must be held in memory in order to execute a correct discrimination (Goldman-Rakic, 1987; Fuster, 1989).

\section{Response selection}

The selective and divided conditions also differ in the type of information used to select a response. This difference can be discussed in two related ways: one functional, the other anatomical. Functionally, decisions in the selective conditions can be made by monitoring a single, or limited, collection of specialized visual processors, while decisions in the divided conditions must be made by a complex polling of multiple channels of visual information or a morc completcly processcd representation of the visual array. Anatomically, responses in the selective conditions might be made on the basis of enhanced signals from extrastriate visual processing areas, while responses in the divided condition may be made on the basis of processing in lateral prefrontal cortex. It appears that these two alternatives entail the use of different premotor or response-selection pathways. In the divided task, dorsolateral frontal activation was coupled with activation of the anterior cingulate, while in the selective task, extrastriate enhancement was coupled with activity in insular cortex and inferior premotor cortex. Both anterior cingulate and lateral premotor areas in primates appear to be heavily interconnected to primary motor cortex (Muakkassa and Strick, 1979; Godschalk et al., 1984; Schell and Strick, 1984; Dum and Strick, 1991).

The correspondence between the use of nonfrontal processors and a premotor-insular output pathway in the selective task has also been found during vocalization of visually or auditorily presented single words (Petersen et al., 1988, 1989). In each of these conditions, efficient response selection can be based on simple or limited processing of input. In the word-repetition condition, the relationship between a visual or auditory word and articulation of that word is an overlearned, efficient association and is mediated, respectively, by left medial extrastriate cortex and parietotemporal cortex (Petersen et al., 1988, 1989, 1990 ). In the selective condition, the information on which the decision is made is limited to a single attribute, perhaps allowing much of the processing to occur in extrastriate cortex.

In contrast, a coupling of frontal and anterior cingulate activity occurred in the divided-attention condition and other complex-task conditions. Activation of the anterior cingulate has been obtained (with a shift of only a few millimeters across different groups of subjects) in conjunction with prefrontal activity in a task in which subjects were asked to generate a verb appropriate to (use for) a given noun (Petersen et al., 1988, 1989), in a semantic monitoring task with high-frequency targets (Posner et al., 1988; Petersen et al., 1989), and in the conflict condition of a Stroop task (Pardo et al., 1990; M. E. Raichle, personal communication). This correspondence suggests that, when response selection cannot be made on the basis of information from "early" posterior processing areas, further processing is done in frontal areas, and the anterior cingulate, rather than opercular regions, is used as the response selection or premotor area.

In the previous comparisons, cingulate activation occurred in the more difficult conditions: divided versus selective, generating a word versus simple repetition, and Stroop conflict versus nonconflict situations. The psychophysical results of this study, however, provide evidence against a task-difficulty interpretation of cingulate function. In terms of measured "difficulty" (task performance as measured by $d^{\prime}$ ), the $d^{\prime}$ for the divided condition averaged across all attributes (which equals the $d^{\prime}$ difficulty during the divided-attention PET scan) is nearly the same as the $d^{\prime}$ during the selective condition for color discrimination. However, in the selection-for-color condition, there is no evidence of cingulate activation, while in the divided condition, there is clear activation.

\section{Functional asymmetry}

A striking difference between human and nonhuman primates is the lateralization of function in the former. Language deficits are most often found following damage to the left hemisphere, whilc spatial neglect is most often stronger following right parietal lesions. Functional asymmetries are also found in the present studies.

For example, some asymmetries (left hemisphere activation stronger than right hemisphere activation) have been found in conditions involving motion analysis, such as presentation of moving dots (Miezin et al., 1987) or high temporal frequencies (F. M. Miezin et al., 1988), and speed discrimination (present results). In the same general location (inferior parietal lobule), anatomical asymmetries have been reported in humans (Eidelberg and Galaburda, 1984). However, areas processing motion information, such as MT and MST, are bilateral in monkey.

Similarly, activation in the anterior temporal lobe for shape attention was clearly stronger on the right side, suggesting functional asymmetry in the processing of shape information in the temporal lobe. Similar right/left asymmetries have been found in temporal cortex during several object recognition tasks (Corbetta et al., 1990b). Functional asymmetries in humans for object discrimination have been also supported by lesion studies. Patients with right temporal lobectomies are impaired in comparison to left temporal lobectomy patients in processing nonverbal patterned material, such as unfamiliar geometric patterns (Kimura, 1963) or faces (Milner, 1968), or in simpler conjunction visual search tasks (Bolster and Birk, 1988).

There are several other examples of differences in activity between analogous structures on the two sides of the brain in 
these tasks, as well. Asymmetrical activations might simply reflect a sensitivity problem in detecting low-level signals or an inability to sample at exactly the same anatomical location in both hemispheres, or they might be related to actual differences in the symmetry of anatomical organization. There is evidence, however, that some asymmetries can be dynamic, reflecting functional interactions between hemispheres. Fox and Applegate (1988) have shown that, while unilateral stimulation of the hand with a vibratory stimulus produces clear contralateral activation to either left or right stimulation alone, much stronger activation is seen on the right side when bilateral stimulation is applied. It appears as if during a competitive situation one hemisphere predominates.

\section{Conclusion}

Selective attention to different visual features modulates activity in distinct regions of extrastriate cortex. Single-unit and lesion data in primates, and lesion and PET data in humans, indicate that these cxtrastriate regions are specialized for processing the selected visual feature. The disjoint pattern of activations in extravisual brain regions during selective- and divided-attention conditions suggests that similar perceptual judgments involve different neural systems, depending on attentional strategies.

\section{References}

Alexander GE, Delong MR, Strick PL (1986) Parallel organization of functionally segregated circuits linking basal ganglia and cortex. Annu Rev Neurosci 9:357-381.

Allport A (1989) Visual attention. In: Foundations of cognitive science (Posner MI, ed), pp 631-682. Cambridge: MIT Press.

Andersen RA (1987) The role of the inferior parietal lobule in spatial perception and visual-motor integration. In: The handbook of physiology, Sec 1, The nervous system, Vol V, Higher functions of the brain, Pt 2 (Plum F, Mountcastle VB, Geiger ST, eds), pp 483-518. Bethesda, MD: American Physiological Society.

Andersen RA (1989) Visual eye movement functions of the posterior parietal cortex. Annu Rev Neurosci 12:377-403.

Asanuma C, Andersen RA, Cowan WM (1985) The thalamic relations of the caudal inferior parietal lobule and the lateral prefrontal cortex in monkeys: divergent cortical projections from cell clusters in the medial pulvinar nucleus. J Comp Neurol 241:357-381.

Bachevalier J, Mishkin M (1986) Visual recognition impairment follows ventromedial but not dorsolateral prefrontal lesions in monkeys. Behav Brain Res 20:249-261.

Bauer RM, Rubens AB (1985) Agnosia. In: Clinical neuropsychology (Heilman KM, Valenstein E, eds), pp 187-241. New York: Oxford UP.

Bender DB (1981) Retinotopic organization of macaque pulvinar. J Neurophysiol 46:672-693.

Benevento LA, Davis B (1977) Topographical projections of the prestriate cortex to the pulvinar nuclei in the macaque monkey: an autoradiographic study. Exp Brain Res 30:405-424.

Benevento LA, Rezak M (1976) The cortical projections of the inferior pulvinar and adjacent lateral pulvinar in the rhesus monkey (Macaca mulatta): an autoradiographic study. Brain Res 108:1-24.

Boch RA, Goldberg ME (1989) Participation of prefrontal neurons in the preparation of visually guided eye movements in the rhesus monkey. J Neurophysiol 61:1064-1084.

Bodamer J (1947) Die Prosop-Agnosie. Arch Psychiatr Nervenkr 179: 6-54.

Bolster RB, Birk P (1988) Effects of focal forebrain injury on featurebased visual search. Soc Neurosci Abstr 14:218

Braitman DJ (1984) Activity of neurons in monkey posterior temporal cortex during multidimensional visual discrimination tasks. Brain Res 307:17-28.

Broadbent D (1982) Task combination and selective intake of information. Acta Psychol (Amst) 50:253-290.

Broadbent DE (1958) Perception and communication. London: Pergamon.
Bruce CJ, Goldberg ME (1985) Primate frontal eye fields. I. Single neurons discharging before saccades. J Neurophysiol 53:603-635.

Bushnell MC, Goldberg ME, Robinson DL (1981) Behavioral enhancement of visual responses in monkey cerebral cortex. I. Modulation in posterior parietal cortex related to selective attention. J Neurophysiol 46:755-772.

Chalupa LM (1977) A review of cat and monkey studies implicating the pulvinar in visual functions. Behav Biol 20:149-167.

Clark S, Miklossy J (1990) Occipital cortex in man: organization of callosal connections, related myelo- and cytoarchitecture, and putative boundaries of functional visual areas. J Comp Neurol 298:188214.

Colby CL, Zeffiro T (1990) Cortical activation in humans during visual and oculomotor processing measured by positron emission tomography (PET). Soc Neurosci Abstr 16:621.

Corbetta M, Miezin FM, Dobmeyer S, Shulman GL, Petersen SE (1990a) Attentional modulation of neural processing of shape, color, and velocity in humans. Science 248:1556-1559.

Corbetta M, Miezin FM, Fox PT, Dobmeyer SM, Petersen SE (1990b) Right infero-temporal cortex PET activation during object recognition tasks in humans. Soc Neurosci Abstr 16:621.

Damasio AR (1985) Disorders of complex visual processing: agnosias, achromatopsia, Balint's syndrome, and related difficulties of orientation and construction. In: Principles of behavioral neurology (Mesulam M, ed), pp 259-288. Philadelphia: Davis.

Damasio AR, Yamada T, Damasio H, Corbet J, McKee J (1980) Central achromatopsia: behavioral, anatomic and physiologic aspects. Neurology 30:1064-1071.

Damasio AR, Damasio H, Van Hoesen GW (1982) Prosopagnosia: anatomic basis and behavioral mechanisms. Neurology 32:331-341.

Desimone R, Schein SJ (1987) Visual properties of neurons in area V4 of the macaque: sensitivity to stimulus form. J Neurophysiol 57: $835-868$.

Desimone R, Schein SJ, Albright TD (1984) Form, color and motion analysis in prestriate cortex of the macaque monkey. In: Pattern recognition mechanisms (Chagas C, Gattass R, Gross C, eds), pp 165172. Vatican City: Pontifical Academy of Sciences.

Desimone R, Schein SJ, Moran J, Ungerleider LG (1985) Contour, color and shape analysis beyond the striate cortex. Vision Res 25: $441-452$.

Desimone R, Wessinger M, Thomas L, Schneider W (1989) Effects of deactivation of lateral pulvinar or superior colliculus on the ability to selectively attend to a visual stimulus. Soc Neurosci Abstr 1:162.

Deutsch J, Deutsch D (1963) Attention: some theoretical considerations. Psychol Rev 70:80-90.

Dubner R, Zeki SM (1971) Response properties and receptive fields of cells in an anatomically defined region of the superior temporal sulcus in the monkey. Brain Res 35:528-532.

Dum RP, Strick PL (1991) The origin of corticospinal projections from the premotor areas in the frontal lobe. J Neurosci 11:667-689.

Duncan J (1980) The locus of interference in the perception of simultaneous stimuli. Psychol Rev 87:272-300.

Duncan J, Humphreys GW (1989) Visual search and stimulus similarity. Psychol Rev 96:433-458.

Egeth H (1967) Selective attention. Psychol Bull 67:41-57.

Egeth HE (1966) Parallel versus serial processes in multidimensional stimulus discrimination. Percept Psychophysiol 1:245-252.

Eidelberg D, Galaburda AM (1984) Inferior parietal lobule. Divergent architectonic asymmetries in the human brain. Arch Neurol 41:843852.

Fox PT, Applegate CN (1988) Right-hemispheric dominance for somatosensory processing in humans. Soc Ncurosci Abstr 14:760.

Fox PT, Mintun MA (1989) Noninvasive functional brain mapping by change-distribution analysis of averaged PET images of $\mathrm{H}_{2}{ }^{15} \mathrm{O}$. J Nucl Med 30:141-149.

Fox PT, Perlmutter JS, Raichle ME (1985) A stereotactic method of anatomical localization for positron emission tomography. J Comput Assist Tomogr 9:141-153.

Fox PT, Miezin FM, Allman JM, Van Essen DC, Raichle ME (1987) Retinotopic organization of human visual cortex mapped with positron emission tomography. J Neurosci 7:913-922.

Fox PT, Mintun MA, Reiman EM, Raichle ME (1988) Enhanced detection of focal brain responses using intersubject averaging and change-distribution analysis of subtracted PET images. J Cereb Blood Flow Metab 8:642-653. 
Fuster JM (1985) The prefrontal cortex and temporal integration. In: Cerebral cortex, Vol 4 (Jones EG, Peters A, eds), pp 151-177. New York: Plenum.

Fuster JM (1989) Prefrontal cortex. Anatomy, physiology, and neuropsychology of the frontal lobe. New York: Raven.

Godschalk M, Lemon RN, Kuypers HGJ, Ronday HK (1984) Cortical afferents and efferents of monkey postarcuate area: an anatomical and electrophysiological study. Exp Brain Res 56:410-424.

Goldman-Rakic PS (1987) Circuitry of primate prefrontal cortex and regulation of behavior by representational knowledge. In: The handbook of physiology, Sec 1, The nervous system, Vol V, Higher functions of the brain, Pt 1 (Plum F, Mountcastle V, eds), pp 373-417. Bethesda, MD: American Physiological Society.

Goldman-Rakic PS (1988) Topography of cognition: parallel distributed networks in primate association cortex. Annu Rev Neurosci 11: 137-156.

Green DM, Swets JA (1966) Signal detection theory and psychophysics. New York: Wiley.

Gross CG (1973) Visual functions of inferotemporal cortex. In: Handbook of sensory physiology (Jung R, ed), pp 77-123. New York: Springer.

Gross CG, Rocha-Miranda CE, Bender DB (1972) Visual properties of neurons in inferotemporal cortex of the macaque. J Neurophysiol 35:96-111.

Haenny PE, Schiller PH (1988) State defendent activity in visual cortex. I. Single cell activity in V1 and V4 on visual tasks. Exp Brain Res 69:225-244.

Haenny PE, Maunsell JIIR, Schiller PH (1988) State dependent activity in monkey visual cortex. II. Retinal and extraretinal factors in V4. Exp Brain Res 69:245-259.

Hawkins HL (1969) Parallel processes in complex visual discrimination. Percept Psychophysiol 5:56-64.

Henik A, Rafal RD, Knight RT (1990) Inhibitory spatial tagging and visual attention: contribution of prefrontal cortex and basal ganglia. Soc Neurosci Abstr 16:579.

Herscovitch P, Markham J, Raichle ME (1983) Brain blood flow measured with intravenous $\mathrm{H}_{2}{ }^{15} \mathrm{O}$. I. Theory and error analysis. $\mathrm{J}$ Nucl Med 24:782-789.

Heywood CA, Cowey A (1987) On the role of cortical area V4 in the discrimination of hue and pattern in macaque monkeys. J Neurosci 7:2601-2617.

Hikosaka O, Wurtz RH (1983) Visual and oculomotor functions of monkey substantia nigra pars reticulata. III. Memory-contingent visual and saccadic responses. J Neurophysiol 49:1268-1284.

Hikosaka O, Sakamoto M, Usui S (1989a) Functional properties of monkey caudate neurons. I. Activities related to saccadic eye movements. J Neurophysiol 61:780-798.

Hikosaka O, Sakamoto M, Usui S (1989b) Functional properties of monkey caudate neurons. III. Activities related to expectation of target and reward. I Neurophysiol 61:799-813.

Jacobsen S, Trojanowski JQ (1977) Prefrontal granular cortex of the rhesus monkey. I. Intrahemispheric cortical afferents. Brain Res 132: 209-233.

Johnston WA, Dark VJ (1986) Selective attention. Annu Rev Psychol 37:43-75.

Jones EG, Powell TPS (1970) An anatomical study of converging sensory pathways within the cerebral cortex of the monkey. Brain 93: 793-820.

Kahneman D, Treisman A (1984) Changing views of attention and automaticity. In: Varieties of attention (Parasuraman R, Davies DR, eds), pp 29-61. New York: Academic.

Kimura D (1963) Right temporal lobe damage: perception of unfamiliar stimuli after damage. Arch Neurol 8:264-271.

Komatsu H, Wurtz RH (1988a) Relation of cortical areas MT and MST to pursuit eye movements. I. Localization and visual properties of neurons. J Neurophysiol 60:580-603.

Komatsu H, Wurtz RH (1988b) Relation of cortical areas MT and MST to pursuit eye movements. III. Interaction with full-field visual stimulation. J Neurophysiol 60:621-644.

LaBerge D, Buchsbaum MS (1990) Positron emission tomographic measurements of pulvinar activity during an attention task. J Neurosci 10:613-619.

Land EH (1974) The Retinex theory of color vision. Proc R Inst $\mathrm{Gr}$ Brit 47:23-58.
Lappin JS (1967) Attention in the identification of stimuli in complex visual displays. J Exp Psychol 75:321-328.

Livingstone MS, Hubel DH (1981) Effects of sleep and arousal on the processing of visual information in the cat. Nature 291:554-561.

Lueck CJ, Zeki S, Friston KJ, Deiber MP, Cope P, Cunningham VJ, Lammertsma AA, Kennard C, Frackowiak RSJ (1989) The colour centre in the cerebral cortex of man. Nature 340:386-388.

Lund JS (1973) Organization of neurons in the visual cortex, area 17, of the monkey (Macaca mulatta). J Comp Neurol 147:455-475.

Maguire WM, Baizer JS (1984) Visuotopic organization of the prelunate gyrus in rhesus monkey. $J$ Neurosci 4:1690-1704.

Maunsell JHR, Newsome WT (1987) Visual processing in monkey extrastriate cortex. Annu Rev Neurosci 10:363-401.

Meadows JC (1974a) The anatomical basis of prosopagnosia. J Neurol Neurosurg Psychiatry 37:489-501.

Meadows JC (1974b) Disturbed perception of colors associated with localized cerebral lesions. Brain 97:615-632.

Miezin F, Applegate C, Petersen S, Fox P (1988) Brain regions in humans activated during smooth pursuit visual tracking. Soc Neurosci Abstr 14:795.

Miezin FM, Fox PT, Raichle ME, Allman JM (1987) Localized responses to low contrast moving random dot patterns in human visual cortex monitored with positron emission tomography. Soc Neurosci Abstr 13:625.

Miezin FM, Fox PT, Raichle ME, Allman JM (1988) An extrastriate region in human visual cortex sensitive to low contrast moving dots and high temporal frequencies. Assoc Res Vis Ophthalmol Abstr 29: 326.

Milner B (1968) Visual recognition and recall after right temporallobe excision in man. Neuropsychology 6:191-210.

Mintun MA, Fox PT, Raichle ME (1989) A highly accurate method of localizing regions of neuronal activation in the human brain with positron emission tomography. J Cereb Blood Flow Metab 9:96-103.

Mishkin M (1966) Visual mechanisms beyond the striate cortex. In: Frontiers of physiological psychology (Russell R, ed), pp 77-123. New York: Academic.

Mishkin M, Manning FJ (1978) Non-spatial memory after selective prefrontal lesions in monkeys. Brain Res 143:313-323.

Mishkin M, Ungerleider LG, Macko KA (1983) Object vision: two cortical pathways. Trends Neurosci 6:414-417.

Moran J, Desimone R (1985) Selective attention gates visual proccssing in extrastriate cortex. Scicnce 229:782-784.

Motter BC, Mountcastle VB (1981) The functional properties of the light-sensitive neurons of the posterior parietal cortex studied in waking monkeys: foveal sparing and opponent vector organization. J Neurosci 7:154-176.

Mountcastle VB, Motter BC, Steinmetz MA, Sestokas AK (1987) Common and differential effects of attentive fixation on the excitability of parietal and prestriate (V4) cortical visual neurons in the macaque monkey. J Neurosci 7:2239-2255.

Muakkassa KF, Strick PL (1979) Frontal lobe inputs to primate motor cortex. Evidence for four somatotopically organized premotor areas. Brain Res 177:176-182.

Newsome WT, Wurtz RH (1981) Response properties of single neurons in the middle temporal visual area (MT) of alert macaque monkeys. Soc Neurosci Abstr 5:825-840.

Newsome WT, Wurtz RH, Komatsu H (1988) Relation of cortical areas MT and MST to pursuit eye movements. II. Differentiation of retinal from extraretinal inputs. J Neurophysiol 5:825-840.

Pardo JV, Pardo PJ, Janer KW, Raichle ME (1990) The anterior cingular cortex mediates processing selection in the Stroop attentional conflict paradigm. Proc Natl Acad Sci USA 87:256-259.

Passingham P (1975) Delayed matching after selective prefrontal lesions in monkeys (Macaca mulatta). Brain Res 92:89-102.

Passingham RE (1972) Visual discrimination learning after selective prefrontal ablations in monkeys (Macaca mulatta). Neuropsychology 10:27-30.

Petersen SE, Robinson DL, Keys W (1985) Pulvinar nuclei of the behaving rhesus monkey: visual responses and their modulation. $J$ Neurophysiol 54:867-886.

Petersen SE, Robinson DL, Morris JD (1987) Contributions of the pulvinar to visual spatial attention. Neuropsychology 25:97-105.

Petersen SE, Fox PT, Posner MI, Mintun M, Raichle ME (1988) Positron emission tomographic studies of the cortical anatomy of singleword processing. Nature 331:585-589. 
Petersen SE, Fox PT, Posner MI, Mintun M, Raichle ME (1989) Positron emission tomographic studies of the processing of single words. J Cogn Neurosci 1:153-170.

Petersen SE, Snyder A, Fox PI, Raichle ME (1990) Activation of extrastriate and frontal cortical areas by visual words and word-like stimuli. Science 249:1041-1044.

Posner MI, Petersen SE (1990) The attention system of the human brain. Annu Rev Neurosci 13:25-42.

Posner MI, Petersen SF, Fox PT, Raichle ME (1988) Localization of cognitive functions in the human brain. Science 240:1627-1631.

Rafal RD, Posner MI (1987) Deficits in visual spatial attention following thalamic lesions. Proc Natl Acad Sci USA 84:7349-7353.

Richmond BJ, Sato T (1987) Enhancement of inferior temporal neurons during visual discrimination. J Neurophysiol 58:1292-1306.

Robinson DL, Goldberg ME, Stanton GB (1978) Parietal association cortex in the primate: sensory mechanisms and behavioral modulations. J Neurophysiol 91:910-932.

Robinson DL, Baizer JS, Dow BM (1980) Behavioral enhancement of visual responses of prestriate neurons of the rhesus monkey. Invest Ophthalmol Vis Sci 19:1120-1123.

Rosenkilde CE, Bauer RH, Fuster JM (1981) Single cell activity in ventral prefrontal cortex of behaving monkeys. Brain Res 209:375394.

Sagar HJ, Sullivan EV, Gabrieli JDE, Corkin S, Growden JH (1988) Temporal ordering and short-term memory deficits in Parkinson's disease. Brain 111:525-539.

Saint-Cyr JA, Taylor AE, Lang AE (1988) Procedural learning and neostriatal dysfunction in man. Brain 111:941-959.

Schein SJ, Marrocco RT, deMonasterio FM (1982) Is there a high concentration of color-selective cells in area V4 of monkey visual cortex? J Neurophysiol 47:193-213.

Schell GR, Strick PL (1984) The origin of the thalamic input to the arcuate premotor and supplementary motor areas. J Neurosci 4:539560 .

Schroeder CE, Givre SJ, Tenke CE, Arezzo JC, Vaughan HG (1989) $V$ isual processing in awake macaques under active and passive conditions. Soc Neurosci Abstr 15:119.

Schwartz EL, Desimone R, Albright TD, Gross CG (1983) Shape recognition and inferior temporal neurons. Proc Natl Acad Sci USA 80:5776-5778

Seltzer B, Pandya DN (1984) Further observations on parieto-temporal connections in the rhesus monkey. Exp Brain Res 55:301-312.

Spitzer H, Desimone R, Moran J (1988) Increased attention enhances both behavioral and neuronal performance. Science 240:338-340.

Taylor AE, Saint-Cyr JA, Lang AE (1986) Frontal lobe dysfunction in Parkinson's disease. Brain 109:845-883.

Thurston SE, Leigh RJ, Crawford T, Thompson A, Kennard C (1988)
Two distinct deficits of visual-tracking caused by unilateral lesions of cerebral cortex in humans. Ann Neurol 23:266-273.

Treisman AM (1969) Strategies and models of selective attention. Psychol Rev 76:282-299.

Ullman S (1984) Visual routines. Cognition 18:97-159.

Ungerleider LG (1985) The corticocortical pathways for object recognition and spatial perception. In: Pattern recognition mechanisms (Chagas C, Gattass R, Gross C, eds), pp 21-37. Vatican City: Pontifical Academy of Sciences.

Ungerleider LG, Mishkin M (1982) Two cortical visual systems. In: Analysis of visual behavior (Ingle DJ, Goodale MA, Mansfield RJW, eds), pp 549-580. Cambridge, MA: MIT Press.

Van der Heijden A (1981) Short-term visual information forgetting. London: Routledge and Kegan Paul.

Van Essen DC (1985) Functional organization of primate visual cortex. In: Cerebral cortex, Vol 4 (Peters A, Jones EG, eds), pp 259-329. New York: Plenum.

Van Essen DC, Zeki SM (1978) The topographic organization of rhesus monkey prestriate cortex. J Physiol (Lond) 277:193-226.

Vogel R, Eeckhout H, Orban GA (1988) The effect of feature uncertainty on spatial discriminations. Perception 17:565-577.

Wise SP, Desimone R (1988) Behavioral neurophysiology: insights into seeing and grasping. Science 242:736-741.

Wurtz RH, Goldberg ME (1972) Activity of superior colliculus in behaving monkey. II. Effect of attention on neuronal responses. $J$ Neurophysiol 35:560-574.

Wurtz RH, Mohler CW (1976) Organization of monkey superior colliculus: enhanced visual response as superficial layer cells. J Neurophysiol 39:745-765.

Wurtz RH, Goldberg ME, Robinson DL (1980) Behavioral modulation of visual responses in monkeys. Psychobiol Physiol Psychol 9: 42-83.

Wurtz RH, Richmond BJ, Newsome WT (1984) Modulation of cortical visual processing by attention, perception, and movement. In: Dynamic aspects of neocortical functions (Edelman GM, Gall WE, Cowan WM, eds), pp 195-217. New York: Wiley.

Yamamoto M, Ficke DC, Ter-Pogossian M (1982) Performance study of PETT VI, a positron computed tomograph with 288 cesium fluoride detectors. IEEE Trans Nucl Sci 29:529-533.

Zeki SM (1973) Colour coding in rhesus monkey prestriate cortex. Brain Res 53:422-427.

Zeki S, Watson JDG, Lueck CJ, Friston KJ, Kennard C, Frackowiak RSJ (1991) A direct demonstration of functional specialization in human visual cortex. J Neurosci 11:641-649.

Zihl J, Von Cramon D, Mai N (1983) Selective disturbance of movement vision after bilateral brain damage. Brain 106:313-340. 